\title{
Sitios en altura y vasijas rotas: reconsiderando la etapa de 'plenitud' de Cogotas I (1450-1150 cal AC) en la Meseta
}

\author{
Hilltop sites and broken vessels: rethinking the later phase of the Cogotas I Culture \\ (1450-1150 cal BC) in the Iberian Meseta
}

\author{
Antonio Blanco González (*)
}

\section{RESUMEN}

Este artículo plantea un ejercicio de autocrítica sobre la comprensión actual del final de Cogotas I en el interior de la Península Ibérica. Diversas dinámicas socio-políticas postuladas para este contexto como la concentración poblacional, la especialización artesanal o la jerarquización social suscitan problemas interpretativos por su deficiente engranaje con la evidencia aducida. Se reúne y escudriña la información contextual disponible sobre los lugares en altura de esta época para elucidar cómo se formaron. Se concluye interpretándolos como sedes estacionales de ceremonias agregativas, fruto de episodios de ocupación intermitentes y reiterados. Las 'biografías culturales' de varios recipientes cerámicos recuperados en hoyos permiten rastrear pautas de abandono complejas, reproducidas tanto en sitios encumbrados como en campos de hoyos en llanura. Ambos enfoques enfatizan la inadecuación de cualquier esquema dualista y simplificador para explicar el registro arqueológico y demandan barajar otras lecturas también posibles.

\begin{abstract}
This paper constitutes a self-critical appraisal on the current understanding of the last centuries of the Cogotas I Culture in inland Iberia. Several socio-political processes posited for this context, such as demographic nucleation, craft specialization and social hierarchization fail to match adequately with the evidence used to test them. We compile the available contextual information on Cogotas I hilltop sites so as to assess their formation cycles. As a result, they are interpreted as seasonal aggregation places, the outcome of intermittent and reiterative occupations for ceremonial purposes. In addition, the 'cultural biographies' of several ceramic vessels
\end{abstract}

(*) Department of Archaeology, University of Durham. South Road DH1 3LE Durham (UK).

Correo e.: ablancoglez@gmail.com

Recibido: 8-I-2013; aceptado: 3-X-2013. retrieved from pits allow us to track similar prescribed and multi-phase gestures performed during their abandonment both in hilltop sites and in lowland pit sites. Both approaches highlight the unsuitability of any kind of dualistic and simplistic readings of the archaeological record and suggest other possible interpretations.

Palabras clave: Península Ibérica; Meseta; Bronce Tardío/Final; Dualidad sitios de llanura-elevados; Procesos formativos; Biografía cultural.

Key words: Iberia; Meseta; Later Bronze Age; Lowland-hilltop sites duality; Formation processes; Cultural biography.

\section{INTRODUCCIÓN}

En las últimas décadas el estudio del final de la Prehistoria Reciente en la Meseta ha gozado de cierto vigor interpretativo. La información arqueológica es muchas veces desconcertante o se recuperó para responder a cuestiones crono-culturales, mucho menos ambiciosas. Sin embargo, ello no ha impedido avanzar sugerentes y atrevidas lecturas en clave funcional y social. Para el final de Cogotas I gran parte de los autores coincide en su diagnóstico: hacia mediados del II milenio AC las comunidades agropastoriles meseteñas habrían alcanzando unos niveles notables de diferenciación social, integración política y división social del trabajo (Almagro-Gorbea 1986: 366-368; Delibes de Castro et al. 1995: 56; Cruz Sánchez 1997: 269-271, 2006/7: 113-116; Díaz Santana 1999: 143; Celis Sánchez 2002: 100-101; Delibes de Castro y Pérez Rodríguez 2002: 53; Delibes de Castro et al. 2007: 120-123, n. 18; Celis Sánchez et al. 2007; Arnáiz Alonso et al. 2012: 518). La dualidad entre numerosas 
ocupaciones en las llanuras y unos pocos sitios elevados es clave en tales propuestas. Los segundos se vienen interpretando como poblados más estables y populosos que los campamentos previos y otros aduares coetáneos del llano (Fernández-Posse 1998: 126-127; González-Tablas y Domínguez Calvo 2002: 226; Delibes de Castro et al. 2007: 122). El acusado contraste entre los 'lugares centrales' y las anodinas estaciones de las planicies estaría marcando los diferentes roles de unos y otros. A los poblados en relieves conspicuos habría fluido el excedente agrario, almacenado en silos, y ciertas materias primas (granito, mineral de cobre) en cantidades que sugieren una producción y abastecimiento a escala regional. Esos sitios ofrecen además indicios de artesanías como la fundición de metales o la preparación y acumulación de molinos, por lo que se ha sugerido su papel aglutinador en el consumo y redistribución de productos básicos. Pero este modelo explicativo, pensado para la Edad del Bronce del sureste (Lull et al. 2010) ¿realmente se compadece con lo conocido en la Meseta?, con la escueta información disponible ¿existe margen para plantear lecturas socio-políticas en tales términos?, ¿pudiéramos estar alcanzando "más interpretación de la que puede hacerse" (Fernández-Posse 1998: 127)? Frente a esta línea interpretativa mayoritaria apenas han surgido visiones alternativas. Díaz-del-Río (2001: 294-298) recordó la falta de nexo causal entre lugares encumbrados y complejidad social, al tiempo que los consideraba dentro de una estrategia de diversificación de los recursos agroforestales y como hitos de agregación social. González Ruibal (2006/07: 95-118) relaciona los sitios arriscados del Bronce Final con preferencias culturales y una nueva fórmula de cohabitar. Recientemente se ha denunciado el desconocimiento de las actividades desempeñadas en tales emplazamientos o la laxitud de su sincronía con las 'alquerías' satélites del llano (Bellido Blanco 2012: 479; Blasco Bosqued 2012: 190-191). Otros autores han señalado la parcialidad de las lecturas consensuadas (Arnáiz Alonso et al. 2012: 517) o han 1lamado la atención sobre el sorprendente parecido entre ciertos sitios en alto y sus asentamientos subordinados (Crespo Díez y Herrán Martínez 2012: 393).

En este artículo se revisan de manera autocrítica algunos pilares de las referidas interpretaciones sobre el final de Cogotas I en la Meseta. Se defiende que tales planteamientos están débilmente imbricados con las estrategias de estudio hasta ahora aplicadas y se insiste en las dificultades de método que debe afrontar su verificación. Además se señalan las limitaciones de la propia evidencia factual y se apuntan algunas vías de avance con resultados prometedores. Ello resulta oportuno porque: 1) es un tema encorsetado en parámetros tradicionales, difíciles de abandonar $\mathrm{y}$ que adolece de una elevada dosis de indefinición y ambigüedad; 2) las lecturas formuladas para esta etapa no consideran adecuadamente las peculiaridades del registro arqueológico y asumen premisas que exigen un escrutinio más riguroso; 3) existe un notable volumen de información inédita procedente de excavaciones, muchas de ellas de urgencia, así como un marco cronológico más preciso, a partir del $\mathrm{C} 14$ por espectrometría de acelerador de masa (AMS), que conviene integrar en la discusión y 4) el examen preliminar de cuestiones hasta ahora inéditas, como la formación de lo que ha quedado de Cogotas I o el ciclo de uso y descarte de su cerámica están ofreciendo pistas para reorientar tales hipótesis de trabajo.

Dos serán los protagonistas de este recorrido: las conocidas cerámicas decoradas y los lugares encaramados. Primero se revisarán los problemas de la inacabada clasificación del repertorio alfarero de Cogotas I. Se recalcará la dificultad que entraña seguir empleando fósiles-directores para distinguir sus últimas alcallerías. Se hará una somera pero ineludible referencia al reciente reajuste de su esquema trifásico: Protocogotas $\rightarrow \mathrm{Co}-$ gotas I Pleno $\rightarrow$ Cogotas I 'Evolucionado'. Frente a esa secuencia consensuada, se ha planteado (Abarquero Moras y Delibes de Castro 2009: 206-209; Esparza Arroyo et al. 2012a: 313) que el radiocarbono solo permite reconocer una etapa inicial (1800-1450 cal AC) y aquellos tres siglos estudiados aquí (1450-1150 cal AC). Tan novedosa perspectiva temporal sugiere repensar los conjuntos cerámicos de 'plenitud' y 'evolucionados' en un escenario de posible convivencia. Sus propiedades físicas y pautas de abandono permiten intuir diferencias entre ambos: un carácter más ubicuo y habitual entre los primeros y un matiz restrictivo, para ocasiones especiales, entre las vasijas más barrocas, hasta ahora consideradas epigonales. Los lugares enriscados donde comparecen tales cerámicas centrarán el consiguiente análisis. La información contextual obte- 
nida en los últimos años -principalmente en la Submeseta Norte- ha reconocido fosas y niveles de ocupación ricos en desperdicios domésticos y artesanales, junto a esporádicas cabañas o cercas de piedra. Una mayor atención a cómo se formaron tales contextos deposicionales ayudará a subrayar su naturaleza problemática. Los sitios en cumbres parecen el resultado de diversas actividades, que de manera discontinua pero repetida han ido dando forma a los restos encontrados. Por último, se recalca la intervención de ciertos convencionalismos en la manipulación de esos desechos, que han condicionado su visibilidad. La observación minuciosa de varias vasijas ha permitido rastrear los avatares experimentados tras su rotura, añadiendo pruebas para difuminar las diferencias entre los campos de hoyos de llanura o en alto.

\section{LA INDEFINICIÓN DEL FINAL DE COGOTAS I}

\subsection{Cerámicas de 'plenitud' y 'avanzadas'}

Los testimonios prehistóricos aquí considerados cuentan con una trayectoria de estudios casi centenaria. Prescindiendo de hallazgos puntuales a finales del siglo XIX en poblados argáricos del sureste peninsular, las primeras cerámicas decoradas de Cogotas I (Fig. 1) fueron recogidas desde los años 1920 en lugares arriscados como Cancho Enamorado (Salamanca) o Las Cogotas (Ávila) (Cabré Aguiló 1929), junto a ejemplares de los areneros aluviales de Valdivia y Martínez (Villaverde, Madrid) (Blasco Bosqued y Lucas Pellicer 2002: 208-216). Su pronta publicación facilitó su protagonismo como elemento diagnóstico de la cultura de Cogotas I (Castro Martínez et al. 1995: 51; Fernández-Posse 1998: 11-12 y fig. 1.1). En los años 1980 una serie de particularismos decorativos fueron dotados de significado temporal para completar así la demarcación interna de esta cultura, según una secuencia trifásica con reminiscencias biológicas: infancia, juventud y madurez (Fernández-Posse 1986/87). Según este esquema, a los antecedentes 'formativos' o Protocogotas seguiría la cerámica de la 'plenitud', y tras ese momento clásico se perfilaba un subconjunto alfarero distintivo, con distintos nombres: fase 'final' o 'terminal' de Cogotas I (Delibes de Castro et al. 1990: 82; Castro Mar- tínez et al. 1996: 157); 'Cogotas I Avanzado' (Fernández-Posse 1986/87: 234; Quintana López y Cruz Sánchez 1996: 15-20); 'Cogotas I Evolucionado' (Barroso Bermejo 2002: 109-114; Abarquero Moras 2005: 34-35; Blasco Bosqued 2012: 195-196) u 'Horizonte San Román de Hornija' (Delibes de Castro et al. 2007: 124; Abarquero Moras y Delibes de Castro 2009: 200).

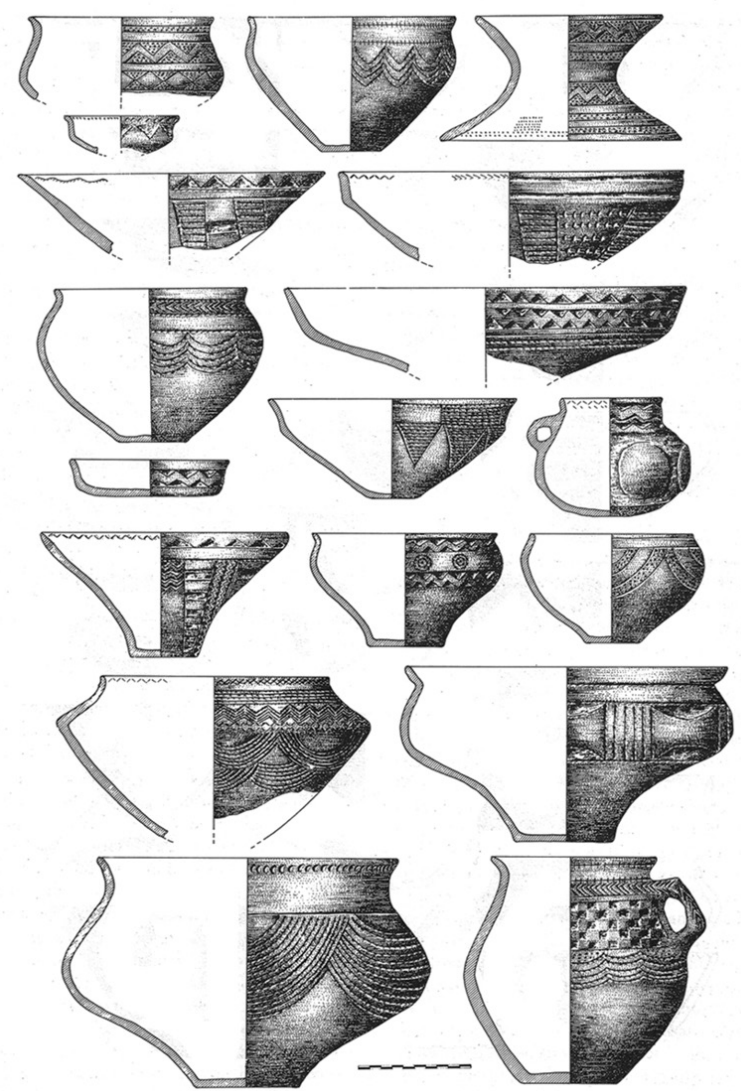

Fig. 1. Selección de formas cerámicas de Cogotas I Pleno y 'evolucionado' (Península Ibérica, Bronce Tardío/ Final) (Fernández-Posse 1986/87: 234, fig. 2).

Ciertos matices ornamentales en la alfarería sirvieron para diferenciar ese último estadio, primero con timidez (Delibes de Castro y Fernández-Miranda 1986/87: 27-28; Fernández-Posse 1986/87: 232-235) y con el aumento del corpus cerámico más resueltamente (Delibes de Castro et al. 1990: 65-66; Fernández Manzano y Palomino Lázaro 1992: 68-70; Quintana López y Cruz Sánchez 1996: 15-20; Rodríguez Marcos 2007: 373-376). Tales atributos formales han per- 
mitido reconocer esa etapa aparentemente postrera (Tab. 1). Así, entre el repertorio fino se suele invocar la presencia de tipos inusuales como rodetes, copas o jarras polilobuladas, la prolijidad de las decoraciones, el predominio de la excisión frente al papel auxiliar del Boquique y la incisión o el empleo ocasional de pasta roja (Tab. 1). En este artículo dicho material cerámico será denominado 'avanzado' para distinguirlo del de 'plenitud'.

Distinguir la alcallería 'plena' de la 'avanzada' ha sido siempre un problema. Aunque la cuantificación de técnicas y motivos ornamentales se ha incrementado y hoy se presta mayor atención al elenco liso y común (Rodríguez Marcos 2007: 338-349), la distinción entre ambos repertorios sigue recayendo en matices ornamentales criticados por estar poco formalizados (Quintana López y Cruz Sánchez 1996: 15-20; Abarquero Moras 2005: 34) y ser minoritarios (Díaz-del-Río 2001: 64). La usual comparecencia de tales cerámicas en hoyos (Delibes de Castro 1978: 237; AlmagroGorbea y Fernández Galiano 1980: 125) ha dificultado el reconocimiento de relaciones estratigráficas con las que secuenciarlas. Su coincidencia en los mismos yacimientos (Quintana López y Cruz Sánchez 1996: 64-66, tab. 1) dificulta asimismo el deslinde. Por último, el propio tratamiento historiográfico de estas cerámicas reproduce dicha ambigüedad: la primera ilustración gráfica de cerámicas de la Fase Media o de 'plenitud', y 'avanzada' (Fernández-Posse 1986/87: 234, fig. 2) mezclaba ambas (Fig. 1). Aportaciones posteriores han seleccionado ejemplares ilustrativos (Abarquero Moras 2005: 34, fig. 7; Barroso Bermejo 2002: 113, fig. 26) o incluyen tablas tipológicas de sitios concretos, como la elaborada para La Requejada (San Román de Hornija, Valladolid) (Delibes de Castro et al. 1990: 104-105, figs. 20 y 21), pero tal vaguedad ha persistido.

En suma, el final de Cogotas I está protagonizado por dos repertorios alfareros, el de 'plenitud' y el 'avanzado', mal definidos, compareciendo muchas veces en los mismos sitios y sin clara superposición estratigráfica. Es posible clasificar motivos decorativos aislados, pero cuesta caracterizar colecciones amplias. Una alternativa al esquema tripartito lineal, especialmente usada en la cuenca del Tajo (Blasco Bosqued y Lucas Pellicer 2002: 205-216; Blasco Bosqued et al. 2007), consiste en incluir las últimas producciones de Cogotas I en un grupo de 'plenitud' solo bien desmarcado de Protocogotas (Rodríguez Marcos 2007: 336-376). La periodización trifásica y sustitutiva de Cogotas I fue tildada ya por su artífice de poco rigurosa (Fernández-Posse 1998: 95) por fundarse en impresiones visuales intuitivas (FernándezPosse 1998: 238-239). Pese a la denuncia de tales inconsistencias (Díaz-del-Río 2001: 52-74) la

\begin{tabular}{|c|c|}
\hline Atributo & Referencia bibliográfica \\
\hline $\begin{array}{l}\text { Tendencia a adoptar perfiles con forma bitroncocóni- } \\
\text { ca o de urna. }\end{array}$ & $\begin{array}{l}\text { Martín Valls y Delibes de Castro 1976: 14; } \\
\text { Delibes de Castro et al. 1990: } 82 \text {. }\end{array}$ \\
\hline $\begin{array}{l}\text { Vasos troncocónicos de base muy estrecha e inesta- } \\
\text { ble, carena alta y borde vuelto. }\end{array}$ & $\begin{array}{l}\text { Martín Valls y Delibes de Castro 1973: 395-402; } \\
\text { Delibes de Castro et al. 1990: 81-82; Iniesta Ayerra 2006: 387-389. }\end{array}$ \\
\hline Tipos peculiares: copas. & Martín Valls y Delibes de Castro 1976: 7-9, fig. 3. \\
\hline $\begin{array}{l}\text { Tipos peculiares: jarritas con gibosidades ornamenta- } \\
\text { das. }\end{array}$ & $\begin{array}{l}\text { Delibes de Castro et al. 1990: 84; Fernández Manzano y } \\
\text { Palomino Lázaro 1992: 69-70; Blasco Bosqued et al. 2002: 320, } \\
\text { fig. } 10.57 \text {. }\end{array}$ \\
\hline $\begin{array}{l}\text { Tipos peculiares: soportes anulares o rodetes de vasar } \\
\text { decorados. }\end{array}$ & $\begin{array}{l}\text { Fernández-Posse 1986/87: 232; Blasco Bosqued y } \\
\text { Lucas Pellicer 2002: } 314 \text {. }\end{array}$ \\
\hline $\begin{array}{l}\text { Vasijas comunes cuya superficie exterior porta dígito- } \\
\text { ungulaciones paralelas. }\end{array}$ & $\begin{array}{l}\text { Delibes de Castro et al. 1990: 80; Quintana López y } \\
\text { Cruz Sánchez 1996: 19; Rodríguez Marcos 2007: } 369 .\end{array}$ \\
\hline $\begin{array}{l}\text { Predominio excisión, papel auxiliar de incisión y Bo- } \\
\text { quique, empleo de pasta roja. }\end{array}$ & $\begin{array}{l}\text { Martín Valls y Delibes de Castro 1972: 12-18; } \\
\text { Fernández-Posse 1986/87: 232-235; Delibes de Castro y } \\
\text { Fernández-Miranda 1986/87: 27-28; Quintana López y } \\
\text { Cruz Sánchez 1996: 19; Blasco Bosqued 2012: } 195 .\end{array}$ \\
\hline
\end{tabular}

Tab. 1. Atributos formales de las cerámicas consideradas más recientes de Cogotas I. 
comodidad de esa plantilla clasificatoria y las dificultades para refutarla explican su aceptación y vigencia. La revisión del significado de la variabilidad ornamental en esta alfarería es hoy una tarea necesaria.

\subsection{Aquilatando la secuencia interna de Cogotas I}

El esquema trifásico de Cogotas I fue formulado antes de que el corpus de información cronológica y contextual alcanzara suficiente entidad, y se soporta en razonamientos asociativos y tipológicos, los únicos entonces disponibles (Fernández-Posse 1986, 1986/87; Delibes de Castro y Fernández-Miranda 1986/87). Solo en los años 1980 comenzó a disponerse de excavaciones modernas y asociaciones cronológicamente significativas (Delibes de Castro 1978: 244-247), incluyendo C14 (Delibes de Castro y FernándezMiranda 1986/87: 22-24). La creciente serie de dataciones radiocarbónicas (1) obtenidas (Castro Martínez et al. 1996: 161-167 y 224; Galán Saulnier 1998; Blasco Bosqued y Lucas Pellicer 2002: 221; Abarquero Moras 2005: 59-68) se ha ido acomodando en la clásica ordenación tripartita sin desajustes (Fig. 2). Hacia mediados de los 1990 Protocogotas quedaba bien delimitado entre 1800/1700-1500/1400 cal AC; la 'plenitud' de Cogotas I comprendía desde mediados del II milenio AC, y la etapa 'avanzada' se acotaba en el intervalo 1150-950 cal AC (Quintana López y Cruz Sánchez 1996: 51; Abarquero Moras 2005: 65; Abarquero Moras y Delibes de Castro 2009: 198; Blasco Bosqued 2012: 192). Sin embargo, semejante escalonamiento crono-tipológico no era tan sólido como aparentaba.

En los últimos años la propuesta lineal trifásica de Cogotas I ha suscitado serias dudas, que afectan especialmente al final de la misma. Ciertas mejoras de la datación radiocarbónica -empleo asiduo de la técnica $A M S$ - y una selección más exigente de las muestras a fechar están en la base de tal cuestionamiento. El rigor del muestreo para radiocarbono de los años 1980 difiere de los protocolos actuales; aquellas dataciones emplearon mayoritariamente carbón vegetal (Castro

(1) Las fechas C14 referidas en el texto se han calibrado con el programa OxCal 4.2 usando la curva Intcal13 (Reimer et al. 2013) y salvo otra indicación se expresan a 2 sigma.

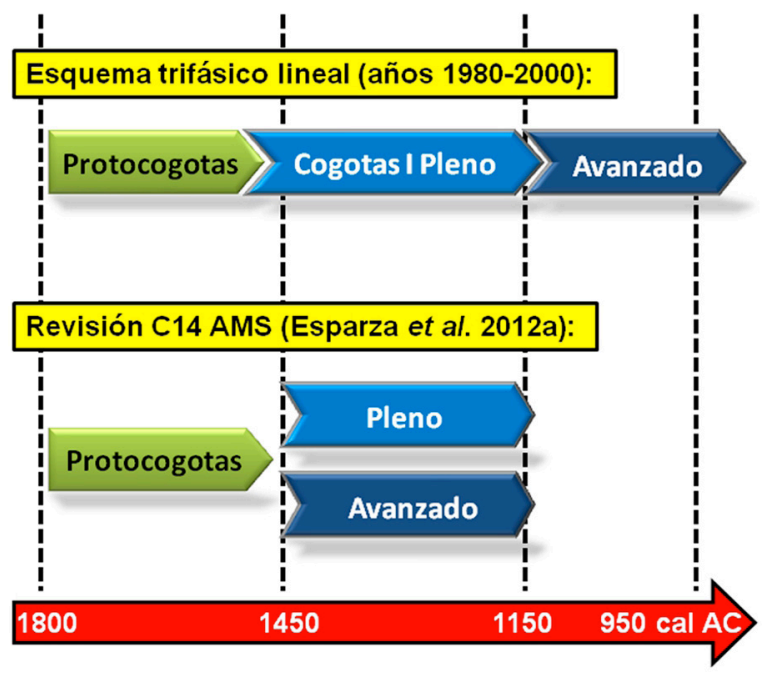

Fig. 2. Relación temporal entre los repertorios de Cogotas I 'pleno' y 'avanzado' según parámetros tradicionales y solapamiento resultante de envejecer el inicio del elenco 'avanzado' (a partir de Esparza Arroyo et al. 2012a).

Martínez et al. 1996: Apéndice VI), cuya problemática -efecto de la madera vieja, reciclaje, procesos post-abandono- es hoy mejor conocida. Así, la datación rutinaria de residuos erráticos en hoyos ha conllevado una correspondencia lábil entre la muerte de la muestra orgánica y los eventos arqueológicos a fechar (Abarquero Moras y Delibes de Castro 2009: 204, n. 4).

Frente a lo mantenido hasta ahora (Castro Martínez et al. 1996: 166; Galán Saulnier 1998: 239-242; Blasco Bosqued 2012: 192) hoy se considera que el final de Cogotas I no alcanzó la última centuria del II milenio AC (Fig. 2). Mederos Martín (2012) tras examinar aquellas dataciones más tardías bien contextualizadas, concluye que no existen testimonios firmes de Cogotas I más modernos de ca. 1100 cal AC. Así lo ha confirmado una nueva batería de muestras radiocarbónicas $A M S$ directas - de vida corta- y de gran calidad -reducida desviación estándar- sobre restos humanos, que ha permitido acotar ambas fases de 'plenitud' y 'avanzada' entre 14501150 cal AC (Esparza Arroyo et al. 2012a: 267-269) (Fig. 2). Es decir, corresponderían al Bronce Medio, Bronce Final I e inicios del Bronce Final II del marco cronométrico de la metalurgia atlántica (Needham et al. 1997), sin prolongación posible en el Bronce Final IIC (Delibes de 
Castro et al. 2007: 124-126; Abarquero Moras y Delibes de Castro 2009: 209-210; Mederos Martín 2012: 75-76). La fase 'avanzada' ha sido la más afectada por este reajuste temporal de Cogotas I (Fig. 2). El sitio vallisoletano de La Requejada está resultando crucial en semejante replanteamiento: su material cerámico se considera representativo de los últimos momentos de esta cultura (Delibes de Castro et al. 1990; Quintana López y Cruz Sánchez 1996: 15-20; Abarquero Moras 2005: 34, fig. 7; Abarquero Moras y Delibes de Castro 2009: 200) y sus fechas C14 lo situaban a finales del II milenio AC (Quintana López y Cruz Sánchez 1996: 51; Abarquero Moras 2005: 66, fig. 13). Tres nuevas dataciones $A M S$ de los tres individuos inhumados simultáneamente en la conocida fosa múltiple (Delibes de Castro 1978) sitúan con seguridad su entierro "ca. 1370-1210 cal AC" (Abarquero Moras y Delibes de Castro 2009: 209, n. 6; Esparza Arroyo et al. 2012a: 313). Así pues, las cerámicas 'avanzadas' comprendidas en el relleno del propio hoyo (Fig. 3), consideradas previas al episodio fúnebre (Castro Martínez et al. 1995: 81; Galán Saulnier 1998: 216), quedarían envejecidas dos siglos frente a la cronología que se les venía adjudicando (Fig. 2).

Los argumentos estadísticos y contextuales para plantear la sincronía entre los materiales 'plenos' y 'avanzados' (Tab. 2) son objeto espe-

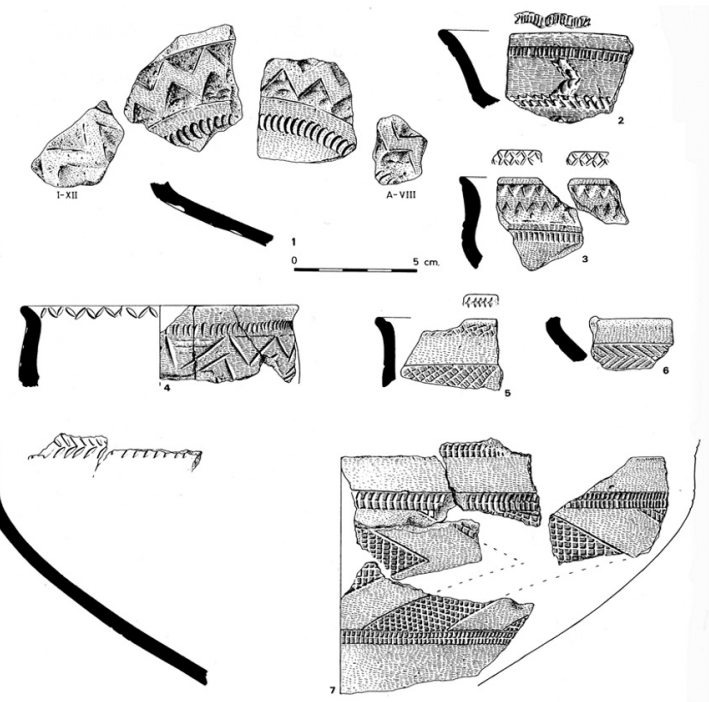

Fig. 3. Cerámica decorada del final de Cogotas I que acompañaba a la inhumación triple en fosa de La Requejada, San Román de Hornija (Delibes de Castro et al. 1990: 98, fig. 14).

cífico de un proyecto de investigación en curso (Esparza Arroyo et al. 2012a) y no pueden discutirse aquí con la profundidad exigida. Tan solo se añadirá que el arco temporal hoy barajado para la fosa fúnebre de La Requejada no es discordante con los valores ofrecidos por otras muestras bien contextualizadas asociadas a materiales ce-

\begin{tabular}{|c|c|c|c|c|c|}
\hline Sitio & Ref. Lab. & Edad BP & Desv. & Calib. $(2 \sigma)$ & Material cerám. asociado \\
\hline Fuente de Boecillo & CSIC-557 & 3170 & 60 & $1525-1270$ & Cogotas I Pleno \\
\hline La Huelga & Beta 71374 & 3160 & 60 & $1520-1270$ & Cogotas I Pleno \\
\hline La Huelga & Beta 71373 & 3080 & 60 & $1445-1130$ & Cogotas I Pleno \\
\hline La Vaquera & CSIC-149 & 3060 & 70 & $1440-1110$ & Cogotas I Pleno \\
\hline Tapado da Caldeira & CSIC-597 & 2990 & 50 & $1390-1030$ & Cogotas I Pleno \\
\hline Cancho Enamorado & Ua-22270 & 3170 & 45 & $1523-1372$ & Cogotas I Avanzado \\
\hline Cueva Espinos & $\mathrm{I}-11117$ & 3120 & 95 & $1495-1270$ & Cogotas I Avanzado \\
\hline El Pelambre & Ua-33609 & 3095 & 40 & $1460-1250$ & Cogotas I Avanzado \\
\hline Hoyas del Castillo & B-5419 & 3050 & 50 & $1430-1130$ & Cogotas I Avanzado \\
\hline La Fábrica de Ladrillos & Beta 197524 & 3000 & 40 & $1430-1270$ & Cogotas I Avanzado \\
\hline
\end{tabular}

Tab. 2. Dataciones ${ }^{14} \mathrm{C}$ asociadas a repertorios de Cogotas I 'pleno' y 'avanzado' (a partir de Abarquero 2005: 62-64 y 471-472, con adiciones): Fuente de Boecillo (Boecillo, Valladolid), La Huelga (Dueñas, Palencia), La Vaquera (Torreiglesias, Segovia), Tapado da Caldeira (Baião, Portugal), Cancho Enamorado (El Tejado, Salamanca), Cueva de los Espinos (Mave, Palencia), El Pelambre (Villaornate, León), Hoyas del Castillo (Pajaroncillo, Cuenca), Fábrica de Ladrillos (Getafe, Madrid). 
rámicos 'avanzados' (Quintana López y Cruz Sánchez 1996: 17-20, fig. 20). Así, las intervenciones de 2003 en Cancho Enamorado (El Tejado, Salamanca) (Fig. 4B: 17) fecharon el relleno de un hoyo con tal material en el rango $c a$. 15231372 cal AC (Ua 22270, $3170 \pm 45$ BP) (López Jiménez y Martínez Calvo 2006). Otro hoyo, el número 55 de El Pelambre (Villaornate, León) (Fig. 4B: 3) procuró una muestra (Ua-33609, $3095 \pm 40$ BP) de vida corta, hueso, asociada a materiales del 'Horizonte San Román de Hornija', fechada ca. 1460-1250 cal AC (Abarquero Moras y Delibes de Castro 2009: 203). Un rango sincrónico ca. 1430-1270 cal AC (Beta 197524, $3000 \pm 40$ BP) fue obtenido del fondo 27 de la Fábrica de Ladrillos (Getafe, Madrid) (Fig. 4A: 4), vinculado a material similar (Blasco Bosqued et al. 2007: 200 y 252-253; Esparza Arroyo 2009: 186). La misma antigüedad queda confirmada en aquellos pocos depósitos estratificados conocidos. En la Cueva de los Espinos (Mave, Palencia) (Fig. 4B: 4) fragmentos cerámicos con ajedrezado exciso se dataron (I-11117, $3120 \pm 95 \mathrm{BP}) \mathrm{ca}$. 1495-1270 cal AC a 1 sigma (Santonja et al. 1982: 371, 380, fig. 19 y 381). Fuera ya de la 'zona nuclear' de Cogotas I, un motivo idéntico al de Mave se reconoce en el estrato 9 de las Hoyas del Castillo (Pajaroncillo, Cuenca) (Fig. 4A: 6), cuya fecha B-5419 (3050 $\pm 50 \mathrm{BP})$ apunta al intervalo ca. 1430-1130 cal AC (Ulreich et al. 1994: 131-132). Por último, en la Cuesta del Negro (Purullena, Granada) (Fig. 4A: 7), una datación de trigo (GrN-7284, $3095 \pm 35$ BP) también sitúa el material Cogotas I 'evolucionado' del estrato VI (Molina González y Pareja López 1975: 187) en momentos antiguos, $c a$. 1435-1288 cal AC.

En el aspecto cronológico son aún muchos los problemas que quedan por resolver, pero pudiera estar cumpliéndose el pronóstico de FernándezPosse (1998: 97) para quien es "el propio método de datación el que a la larga va a desmontar esos enmarques cronológicos". El perfecto acomodo entre fechas absolutas y seriación tipológica, antes que reflejar la corrección del método mostraba más bien la inercia de unos esquemas preconcebidos. La incorporación de determinadas formas o decoraciones cerámicas pudo ser consecutiva y carecemos aún de suficiente resolución temporal para acotarla. Sin embargo, la información adelantada (Esparza Arroyo et al. 2012a) obliga a considerar un escenario inadvertido, más complejo y rico en matices. Las manifestaciones propias de la 'plenitud' y aquellas 'avanzadas', que se venían considerando posteriores (Fig. 2), en realidad pudieran haber convivido durante varios siglos a finales del Bronce Medio y durante el Bronce Final I y II del marco cronológico extrapeninsular. El inicio de la vajilla más barroca se alejaría del año 1000 cal AC (Abarquero Moras y Delibes de Castro 2009: 206) para acercarse inusitadamente a mediados del II milenio AC. "En rigor, a lo largo de Cogotas I deberían reconocerse solo dos fases, Protocogotas y Plenitud, y el hecho de que en la segunda se recurra (...) a una mayor o menor sofisticación en la decoración cerámica, sería algo a interpretar al margen del factor tiempo" (Esparza Arroyo et al. 2012a: 313).

\section{EL REGISTRO MATERIAL DEL FINAL DE COGOTAS I}

\subsection{Explorando la distribución de las cerámicas}

Plantear la coexistencia de las cerámicas de 'plenitud' y 'avanzadas' requiere una mínima evaluación de los datos disponibles. Un simple cotejo numérico de ambas atribuciones tipológicas a nivel territorial ofrece ya un primer panorama. Ello, a pesar de las deficiencias de tal clasificación, basada en atributos minoritarios según un discutible criterio de presencia/ausencia, sobre muestras muy desiguales y sin ponderar la variabilidad debida a preferencias regionales. Así, el estudio de Quintana López y Cruz Sánchez (1996: 64-68) sobre la provincia de Valladolid arrojaba el cómputo de 67 sitios de 'plenitud' frente a 9 con materiales 'avanzados'. En la 'zona nuclear' de Cogotas I, Abarquero Moras (2005: 86, fig. 17) reconocía la presencia de 188 lugares de Cogotas I Pleno frente a 22 con material 'avanzado', mientras que en las 'zonas de expansión' el repertorio 'clásico' o de 'plenitud' se identifica en 80 sitios frente a los 22 con material 'avanzado' (Abarquero Moras 2005: 467, fig. 105). Los datos actualizados para toda la Submeseta Norte que manejamos aquí confirman tal desproporción: en 377 localizaciones se reconocen materiales 'plenos' frente a 34 casos 'avanzados' (Fig. 4B). Es decir, por cada 11 lugares con material de 'plenitud' encontramos 1 sitio con cerámicas 'avanza- 


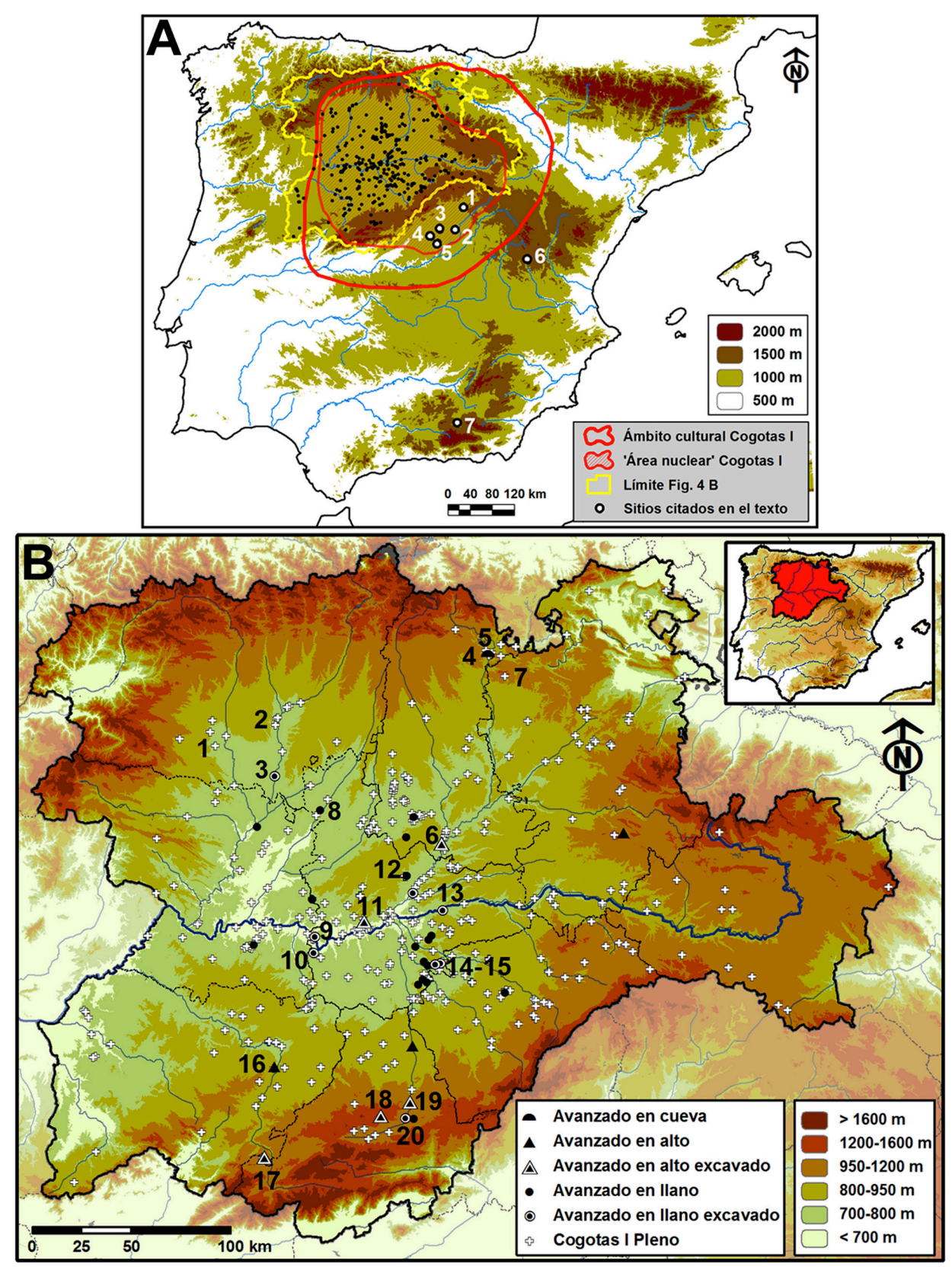

Fig. 4. A. Sitios del final de Cogotas I (1450-1150 cal AC) citados en el texto, sobre modelo digital de elevaciones (MDE) SRTM (Shuttle Radar Topography Mission) de la NASA: 1. La Muela (Alarilla, Guadalajara); 2. Ecce Homo (Alcalá de Henares, Madrid); 3. Valdivia y Martínez (Villaverde, Madrid); 4. Fábrica de Ladrillos (Getafe, Madrid); 5. El Caserío de Perales del Río (Getafe, Madrid); 6. Hoyas del Castillo (Pajaroncillo, Cuenca); 7 . Cuesta del Negro (Purullena, Granada). B. Sitios en Castilla y León (a partir de Quintana López y Cruz Sánchez 1996: 45, fig. 8; Abarquero 2005: 74-85, con adiciones): 1. Castro de Sacaojos (La Bañeza, León); 2. El Castro (Ardón, León); 3 . El Pelambre (Villaornate, León); 4. Cueva de los Espinos (Aguilar de Campoo, Palencia); 5. Los Baraones (Aguilar de Campoo, Palencia); 6. Pico Castro (Dueñas, Palencia); 7. Peña Amaya (Amaya, Burgos); 8. Pórragos (Bolaños de Campos, Valladolid); 9. La Requejada (San Román de Hornija, Valladolid); 10. Mucientes/San Lázaro (Castronuño, Valladolid); 11. Carricastro (Tordesillas, Valladolid); 12. Piedrahita (Mucientes, Valladolid); 13. Soto de Tovilla II (Tudela de Duero, Valladolid); 14. Prado Esteban (Pedrajas de San Esteban, Valladolid); 15. Las Cotarrillas (Íscar, Valladolid); 16. Mesa de Carpio (Villagonzalo de Tormes, Salamanca); 17. Cancho Enamorado (El Tejado, Salamanca); 18. Los Castillejos (Sanchorreja, Ávila); 19. Las Cogotas (Cardeñosa, Ávila); 20. Cerro de la Cabeza (Ávila).

Trab. prehist., 71, N. ${ }^{\circ}$ 2, julio-diciembre 2014, pp. 305-329, ISSN: 0082-5638 doi: $10.3989 /$ tp.2014.12136 
das'. A escala peninsular la proporción es de 8 a 1 , con 457 conjuntos de 'plenitud' frente a 56 yacimientos con cerámicas 'avanzadas'.

El emplazamiento donde comparecen los repertorios de 'plenitud' son tanto sitios en altura como Los Baraones (Valdegama, Palencia) (Barril Vicente 1995: 400-401 y 405-406); el Castro de Sacaojos (La Bañeza, León) (Misiego et al. 1999: 43-52); El Castro (Ardón, León) (Celis Sánchez 2007: 140-147) o Peña Amaya (Amaya, Burgos) (Quintana López y Estremera Portela 2008: 112-117) como, mayoritariamente, las llanuras sedimentarias: la Fábrica de Ladrillos (Getafe, Madrid) (Blasco Bosqued et al. 2007) o El Pelambre (Abarquero Moras y Delibes de Castro 2009). El material 'avanzado' también se reconoce en riscos graníticos y plataformas calizas (Fig. 4), analizados en la siguiente sección, así como en el llano, caso de La Requejada (Delibes de Castro 1978; Delibes de Castro et al. 1990); los madrileños del Caserío de Perales del Río (Getafe) (Iniesta Ayerra 2006) o la Fábrica de Ladrillos (Blasco Bosqued al. 2007) y lugares vallisoletanos como Las Cotarrillas (Íscar) (Quintana López y Cruz Sánchez 1996: 18 y 64), Prado Esteban (Pedrajas de San Esteban) (Quintana López y Cruz Sánchez 1996: 65) o Mucientes/ San Lázaro (Castronuño) (Aratikos 2012) (Fig. 4). No existe pues correspondencia entre la topografía del lugar y la tipología del material cerámico.

\section{2. ¿Qué albergaron los lugares encumbrados?}

Este epígrafe pretende abordar la pregunta que le sirve de título, recientemente planteada de nuevo (Bellido Blanco 2012: 479; Blasco Bosqued 2012: 190-191). Hasta hace poco los sitios enriscados (Fig. 5) se conocían por datos de superficie (Cruz Sánchez 1997, 2006/7) o por discretos sondeos estratigráficos realizados en los años 1980. Es el caso del Ecce Homo (Alcalá de Henares, Madrid) (Almagro Gorbea y Fernández Galiano 1980: 17-25) con apenas tres 'fondos' conocidos del Bronce Final, muy afectados por alteraciones post-abandono (Díaz-del-Río 2001: 271-274). Las excavaciones en La Muela (Alari1la, Guadalajara) (Méndez Madariaga y Velasco Steigrad 1984: 8-12) reconocieron hoyos y también "grandes estructuras de habitación para la última fase de Cogotas" (Méndez Madariaga
1994: 122). Por entonces también se intervino en El Castro (Ardón, León), documentándose de nuevo fosas (Celis Sánchez 2007: 140-147). Mayor interés presenta Los Castillejos (Sanchorreja, Ávila) (Figs. 4B: 18 y 5B). A partir de la documentación de las excavaciones pioneras de 19321933, Maluquer de Motes (1958a: 27-34) reconstruyó diecisiete fondos u hoyos, denominados Sa1 a Sa17, del 'barrio extramuros', interpretados como chozas. Sin embargo, ni su funcionalidad ni su cronología resisten un análisis actual. Las excavaciones de 1988 en aquel mismo punto permitieron releer las chozas $\mathrm{Sa} 1$ a $\mathrm{Sa} 5$ de 1932 (Maluquer de Motes 1958a: 22-24, fig. 7) como estructuras de una necrópolis tumular del Hierro Inicial (González-Tablas 1990; Fernández Gómez 1995: 115-116). Trabajos más modernos tampoco confirmaron la presencia de verdaderas cabañas. En 1981 se exhumaron en el sector IV dos estructuras superpuestas en apenas $12 \mathrm{~m}^{2}$, cabaña Sa18, con una secuencia de cuatro niveles con materiales mezclados de Cogotas I y del Hierro Inicial ya desde la base. Solo el nivel IVc correspondería al suelo de preparación de la 'vivienda inferior', atribuida al Bronce Final (González-Tablas y Domínguez Calvo 2002: 37-45, figs. 26 y 27). Tan parca e incompleta información no respalda el destino de los fondos como viviendas, ni asegura su apertura y condena durante el Bronce Final.

En la cumbre del Cerro del Berrueco (El Tejado, Salamanca) (Fig. 4B: 17), Maluquer de Motes (1958b: 30-33, fig. 5) excavó entre 1953 y 1956 las chozas Be1 a Be6, tres en cada sector contiguo de la plataforma superior: la Casa del Santo a occidente y Cancho Enamorado a oriente (Fig. 6). La campaña de 2003 (2) permitió reubicar siete catas: Be4, Be5 y Be6 en el extremo oriental de Cancho Enamorado y cuatro, incluyendo Be1, B2 y Be3, en la plataforma inferior, en la vertiente meridional del cerro (Fig. 6C). Solo Be1 y Be2, en la falda mejor resguardada y soleada, son verdaderas estructuras de hábitat, tal como interpretó Maluquer de Motes (1958b: 32, fig. 5 y láms. I-VIII). Tres de los cuatro sondeos emprendidos en 2003 se centraron en la plataforma superior, otro en la ladera meridional y se

(2) López Jiménez, O. 2003: Memoria de los trabajos realizados en la Zona Arqueológica del Cerro del Berrueco (El Tejado-Puente del Congosto, Salamanca). Documento inédito consultable en el Servicio Territorial de Cultura de Salamanca. 

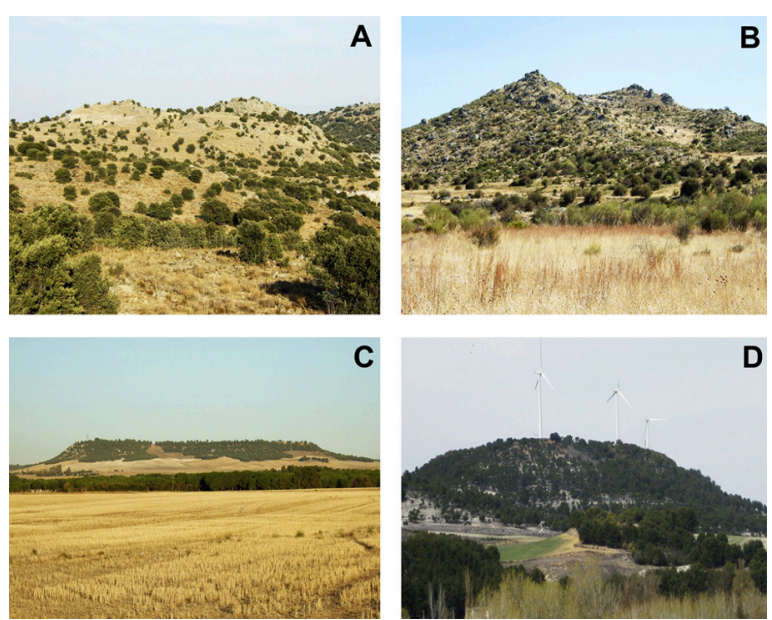

Fig. 5. Lugares en altura excavados con material 'avanzado' de Cogotas I en la Submeseta Norte. A. Las Cogotas (Cardeñosa, Ávila), B. Los Castillejos (Sanchorreja, Ávila), C. Carricastro (Tordesillas, Valladolid). D. Pico Castro (Dueñas, Palencia). Fotos A. Blanco. limpió la cabaña Be1 exhumada en 1956 (López Jiménez y Martínez Calvo 2006). En la cata CA-A se documentó un parapeto de piedra en seco de $4 \mathrm{~m}$ de anchura, que aísla el extremo occidental de la Casa del Santo (Fig. 6C). En CA-B, en el interior de ese recinto, se reconoció el pavimento de tierra de una cabaña sobre el que yacían cuatro fragmentos óseos humanos y un cuenco completo con Boquique. En el extremo contrario de Cancho Enamorado, el sondeo CB-A permitió recuperar abundante material cerámico del Bronce Antiguo y Cogotas I. Por último, en CB-B, en la falda sureste del cerro, a mayor altitud que las catas de los años 1950, se detectó una cabaña de pavimento apisonado con abundante vajilla Cogotas I, junto a dos espirales, un cincel y una punta de flecha de bronce binario (López Jiménez y Martínez Calvo 2006).

Recientemente se han excavado otros lugares en alto con materiales propios del final de Cogo-

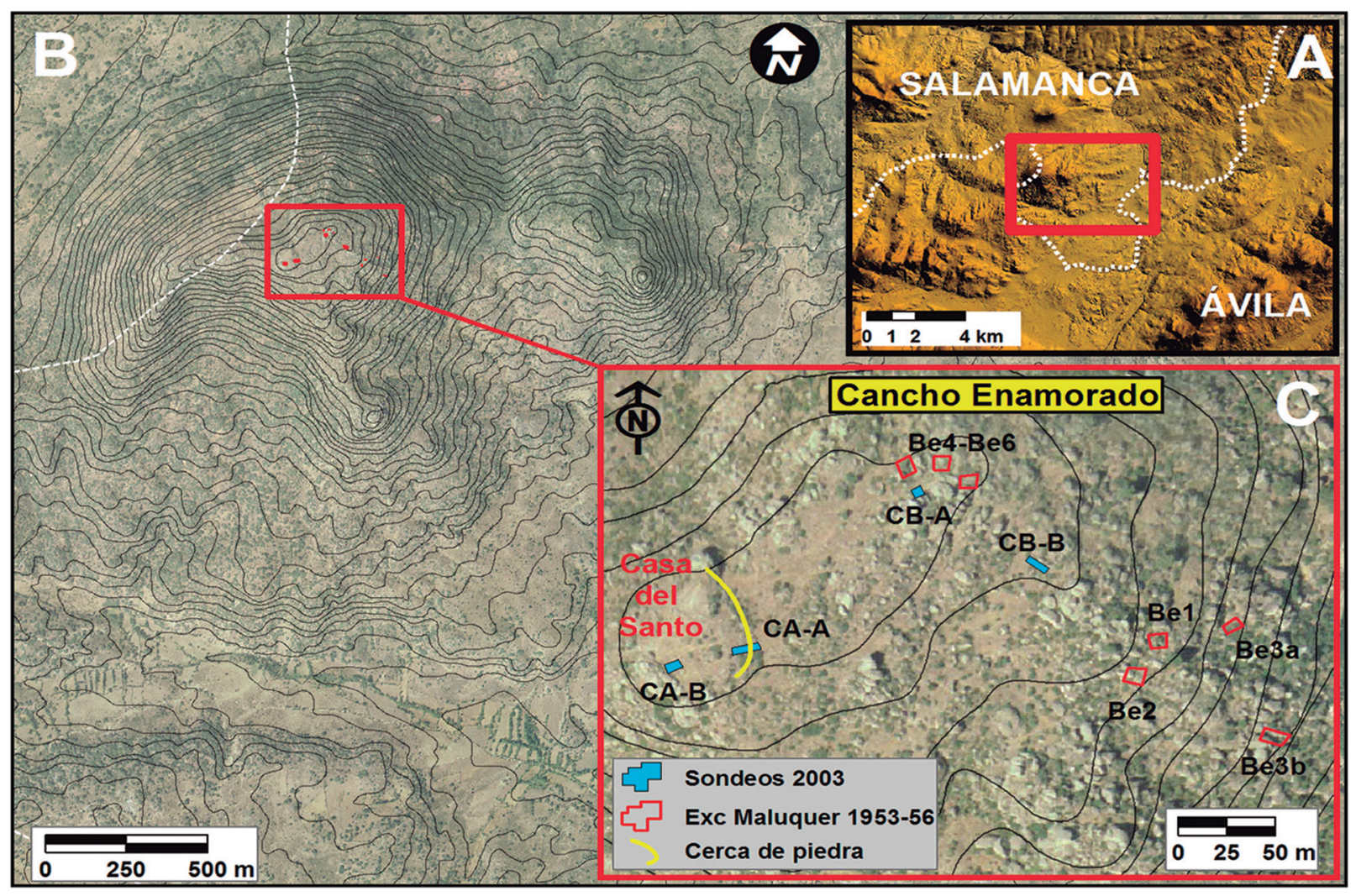

Fig. 6. A. Ubicación del Cerro del Berrueco (El Tejado, Salamanca) sobre el MDE SRTM de la NASA. B. Localización de Cancho Enamorado en la cima del Cerro del Berrueco sobre ortofotografía de 2010 del PNOA y mapa topográfico 1:10.000 de la Junta de Castilla y León. C. Sondeos antiguos (Be) y modernos (CA, CB) en Cancho Enamorado (a partir de López Jiménez 2003: fig. 5, en nota 2) sobre ortofotografía del PNOA y mapa topográfico de la JCyL.

Trab. prehist., 71, N. ${ }^{\text {o }}$, julio-diciembre 2014, pp. 305-329, ISSN: 0082-5638 doi: 10.3989/tp.2014.12136 
tas I. En Peña Amaya (Amaya, Burgos) (Quintana López y Estremera Portela 2007: 112-117) se constató un nivel arqueológico con cerámicas de Cogotas I 'pleno' en la cata 18 de la plataforma culminante de La Peña, en el sector donde se halló un fragmento de espada pistiliforme (Fernández Manzano 1986: 100, fig. 29, 1). En Pico Castro (Dueñas, Palencia), un sitio bien conocido (Calleja González 1975; Delibes de Castro y Pérez Rodríguez 2002: 53; Delibes de Castro et al. 2007: 120, n. 17; Blanco González 2014) la instalación de cuatro aerogeneradores y una subestación eléctrica (Figs. 5D y 4B: 6) motivó la excavación de $715 \mathrm{~m}^{2}$ en los cinco sectores afectados en 2005 (3) y el control arqueológico de la zanja lineal para albergar el cableado que los conecta (Fig. 7). Solo se encontraron hoyos cavados en el sustrato calizo, distribuidos por las 12 has de la cima plana del yacimiento: 46 fosas en las cinco catas y un centenar al supervisar la remoción mecánica de la zanja. La densidad de pozos aumenta hacia el extremo meridional del cerro, un espigón estrecho y plano con una espléndida vista sobre la confluencia de los ríos Carrión y Pisuerga (Fig. 7). En este sector V se excavó el hoyo 23, que rindió un conjunto de vasijas que trataremos después. Del contiguo sector IV, el hoyo 18 deparó un fragmento de chapa de bronce, probablemente de un caldero (4) y la fosa S-38 restos de dos personas: un infante muerto en el intervalo aquí considerado, y un adulto fallecido varios siglos antes (Esparza Arroyo et al. 2012b: 120). En este sitio los restos humanos parciales son frecuentes (Esparza Arroyo et al. 2012a: 272). En el extremo contrario, sector I, el pozo S-3 contiene cinco molinos de granito y fragmentos de otros seis, reunidos allí deliberadamente. Por último, en Carricastro (Tordesillas, Valladolid) (Fig. 5C) considerado un 'lugar central' por su emplazamiento y extensión y sus singulares hallazgos metálicos (Delibes de Castro et al. 2007: 118-123; Herrán Martínez

(3) Crespo Díez, M.; Herrán Martínez, J. I. y Puente Aparicio, M. ${ }^{\mathrm{a}}$ J. 2005a: Intervención Arqueológica en el Pico Castro, Dueñas, Palencia. Abril-Mayo de 2005. Excavación de Sondeos Arqueológicos. Crespo Díez, M.; Herrán Martínez, J. I. y Puente Aparicio, M. ${ }^{\mathrm{a}}$ J. 2005b: Intervención Arqueológica en Pico Castro, Dueñas, Palencia. $2 .{ }^{a}$ Fase Octubre-Noviembre de 2005. Trabajos de Seguimiento Arqueológico. Documentos inéditos consultables en el Servicio Territorial de Cultura de Palencia.

(4) Véase Crespo Martín et al. 2005a, pág. 47 en nota 3.
2008: 160-163 y 519-521), la ubicación de 9 aerogeneradores en la cima planteó la ejecución de sondeos en 2009 para documentar previamente $\operatorname{los} 5.000 \mathrm{~m}^{2}$ afectados. Se detectaron 63 hoyos y 5 agujeros de poste desigualmente repartidos por las 30 has del teso, con mayor densidad en su zona central (Crespo Díez y Herrán Martínez 2012).

En suma, los sitios examinados acogieron actividades diversas y no responden a un plan uni-

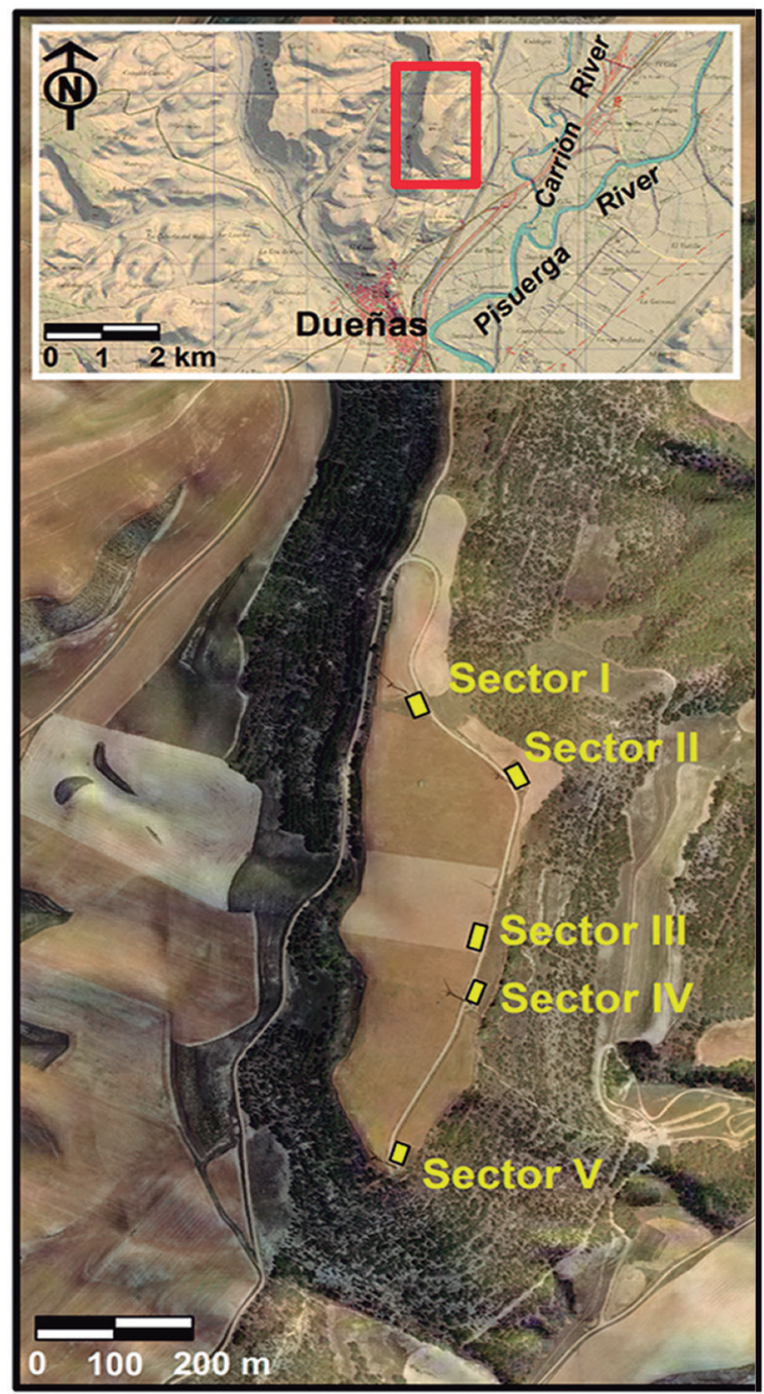

Fig. 7. Localización de las catas de 2005 en Pico Castro (Dueñas, Palencia), poblado en alto con materiales del final de Cogotas I (M. Crespo Díez, J. I. Herrán Martínez y M. ${ }^{\mathrm{a}} \mathrm{J}$. Puente Aparicio, com. pers.) sobre MDE SRTM de la NASA y ortofotografía de 2007 del PNOA. 
tario. Las plataformas calizas están salpicadas por hoyos tallados en el sustrato, también documentados en los riscos graníticos. Se confirma la existencia de cabañas en Cancho Enamorado (López Jiménez y Martínez Calvo 2006) y se sostiene su presencia en La Muela de Alarilla (Méndez Madariaga 1994: 122), mientras que en Los Castillejos (González-Tablas y Domínguez Calvo 2002: 37-45) y Carricastro (Crespo Díez y Herrán Martínez 2012: 386-387) las pruebas aportadas son aún insuficientes. Los voluminosos muros de piedra en seco, que cabe llamar cercas mejor que murallas, en Cancho Enamorado o Los Castillejos perpetúan un tipo de estructura reconocida durante la fase Protocogotas (Rodríguez Marcos 2007: 434-436). Pero estructuras y fosas siguen siendo esquivas sin una mínima referencia a los ritmos y las lógicas de uso y descarte de restos en tales lugares.

\section{3. ¿Cómo se formaron los sitios en alto?}

El ciclo formativo (Jiménez Jáimez 2008) de los contextos que estamos discutiendo ha sido un aspecto hasta ahora desatendido. Una primera cuestión a tratar es la duración de las ocupaciones y la cadencia de sedimentación seguida. En Pico Castro una costra grisácea en las paredes de algunos hoyos se ha interpretado como resultado de la meteorización de la caliza y mostraría cierto lapso temporal transcurrido entre su apertura y relleno. La ausencia de intersecciones entre fosas prueba además el reconocimiento de las existentes y una mínima ordenación espacial (5). En cambio, en Carricastro la clausura de los hoyos pudo ser más rápida, y los numerosos recortes indican sucesivas fases de actividad sin recuerdo de los depósitos previos (Crespo Díez y Herrán Martínez 2012: 384, 387-389, fig. 4). He estudiado el material de los sectores IV y V de Pico Castro, distantes $230 \mathrm{~m}$ entre sí (fig. 7), con la metodología ensayada con éxito en sitios prehistóricos británicos de similar problemática (Brudenell y Cooper 2008). Seis de las 14 fosas comprendidas en el sector $\mathrm{V}$ contenían fragmentos de los mismos recipientes, por lo que pudieron usarse a la par y finalmente se rellenaron con sedimentos y materiales compartidos. Siguiendo este

(5) Crespo Martín et al. 2005a, págs. 71-72 en nota 3. criterio, solo unos pocos hoyos fueron clausurados en cada fase de actividad. En ese extremo meridional del teso (Fig. 7) numerosas piezas cerámicas casan entre sí y presentan fracturas frescas, por lo que fueron descartadas poco antes de su incorporación a los hoyos. Pero también hay material erosionado y menudo, claramente secundario e incluso terciario, es decir desechado, recuperado y redepositado de nuevo (Morris y Jervis 2011: 70, n. 32). La dinámica de colmatado de pozos en el sector IV fue distinta, con una mayor proporción de fragmentos 'huérfanos' (Schiffer 1987: 298-302) y material residual, lo cual indica acciones de clausura independientes en zonas relativamente próximas del yacimiento (Fig. 7). Algo similar se observó en Cancho Enamorado (Fig. 6C): en la Casa del Santo (sondeo CA-B) "los materiales parecen depositados, en muy buen estado de conservación" mientras que la fauna de CB-A presenta afecciones tafonómicas distintas (López Jiménez y Martínez Calvo 2006).

En segundo lugar, necesitamos caracterizar la génesis de los contextos deposicionales en tales sitios (6). Para ello, frente a planteamientos demasiado restrictivos (Schiffer 1987) nos aproximaremos a la rica variabilidad del registro arqueológico tratando de caracterizar sus 'historias deposicionales' (Brudenell y Cooper 2008; Morris y Jervis 2011; Garrow 2012). Tal enfoque comparativo pretende evitar selecciones a priori y abordar con mayor flexibilidad los procesos antropogénicos y naturales que concurrieron en un mismo lugar (Brudenell y Cooper 2008). Ello permite reconocer una gradación de situaciones entre dos extremos ideales o arquetípicos (Garrow 2012: 94 y 106): 1) los resultantes de prácticas de descarte asimiladas y rutinarias, reproducidas de manera expeditiva e inconsciente, y 2) aquellos conjuntos fruto de gestos ejecutados con conciencia explícita, persiguiendo un resultado físico premeditado. La mayoría de los contextos reconocidos en los lugares encumbrados estarían más próximos al primer tipo. Son vertidos resultantes de actividades de remoción y refacción antrópicas, muchas veces repartidas en un tiempo laxo: niveles de terraplenado, cimentación y erección de estructuras y rellenos de fosas que con-

(6) Para una excelente discusión actualizada sobre los temas aquí tratados cf. Lucas 2012.

Trab. prehist., 71, N. ${ }^{\circ}$ 2, julio-diciembre 2014, pp. 305-329, ISSN: 0082-5638

doi: $10.3989 /$ tp.2014.12136 
tienen material residual de arrastre o desechos inadvertidos redepositados (Schiffer 1987: 2832). Tales acumulaciones de despojos, que incluyen materiales con diversa temporalidad, podrían comprenderse mejor desde conceptos del mundo de la tafonomía y los procesos formativos arqueológicos, como los de 'palimpsesto' o 'colecciones temporalmente promediadas' (time averaged assemblages, Lucas 2012: 91-123). Ciertos conjuntos cumplen además dos criterios de la noción de 'agregados de desechos secundarios' (Wilson 1994: 44-45): a) extraídos de su contexto funcional o primario y $b$ ) distinguibles por su frecuencia y densidad. El carácter desplazado de dichos restos ha quedado probado en el nivel de preparación de la cabaña en la Casa del Santo, cata CA-B, y en la gruesa cerca de cierre de ese sector, sondeo CA-A (Fig. 6C), al emplear abundantes cerámicas erosionadas, esquirlas de fauna y once molinos barquiformes amortizados (7). Este término también ayudaría a interpretar la presencia en tales lugares de cerámicas Protocogotas, en muestras siempre muy reducidas: unas 20 piezas en Las Cogotas (Cabré Aguiló 1929: 239, 243-244); 6 fragmentos en Pico Castro; 10 en Cancho Enamorado (Fabián García 2012: 326327, fig. 8) y 2 en Carricastro (Crespo Díez y Herrán Martínez 2012: 389 y 393). Respecto a la frecuencia del material en tales depósitos, en Cancho Enamorado se registraron 7.622 fragmentos cerámicos en los $65 \mathrm{~m}^{2}$ exhumados en 2003 (8), en su inmensa mayoría del Bronce Final. En Pico Castro se recuperaron 4.477 trozos de vasijas en las 46 fosas excavadas en $715 \mathrm{~m}^{2}$. Estas cantidades de cerámica con decoración 'avanzada' representan un notable contraste frente a lo conocido en los sitios de llanura, donde tales colecciones escasean (Blasco Bosqued et al. 2007: 72; Sánchez Polo 2012: 86).

Otros contextos deposicionales minoritarios se situarían en el polo opuesto (Garrow 2012), al responder a un mayor grado de intencionalidad. Es el caso de hoyos tan peculiares como el 23 o el S-33 de Pico Castro, según veremos. Este supuesto también es aplicable a ciertos niveles de ocupación asociados a las cabañas mencionadas, que son producto de complejos procesos de adición y reducción de sedimentos y restos de cul-

(7) López Jiménez 2003: pág. 31, en nota 2.

(8) López Jiménez 2003, pág. 43 y Anexo I, en nota 2. tura material (Jiménez Jáimez 2008: 128-133). En tales espacios se reconocen indicios de abandono pautado, como los recipientes completos y los restos humanos sobre el suelo de la cabaña de la Casa del Santo (López Jiménez y Martínez Calvo 2006). La inclusión de tales materiales no parece casual: la manipulación de restos humanos sueltos, tanto en Cancho Enamorado como en Pico Castro, constituye una práctica cultural distintiva, dentro de un fenómeno de circulación de reliquias ancestrales, tal como ha confirmado el C14 en Pico Castro (Esparza Arroyo et al. 2012a: 272; Esparza Arroyo et al. 2012b: 120). Tampoco parece azarosa la presencia de un lote de útiles de bronce sobre el pavimento de la cabaña de CB-B en Cancho Enamorado (López Jiménez y Martínez Calvo 2006) (Fig. 6C). No sólo los productos finalizados fueron abandonados de este modo: los residuos de diversas fases de elaboración de artesanías como el tejido, la molienda, la talla lítica o la metalurgia parecen haber sido descartados siguiendo unos convencionalismos destinados a singularizar dichas tareas (Sánchez Polo 2012: 85-87).

En definitiva, estamos ante ritmos y dinámicas de acumulación heterogéneos. Los lugares encumbrados parecen fruto de trayectorias singulares, resultado de la compleja interacción de factores naturales y culturales (Schiffer 1987; Chapman y Gaydarska 2007: 71-79; Rosenwig 2009: 3). En conjunto, las tasas de sedimentación observadas en Carricastro (Crespo Díez y Herrán Martínez 2012: 389), Cancho Enamorado (López Jiménez y Martínez Calvo 2006) y Pico Castro indican ocupaciones breves pero reiteradas. Tales sitios serían pues el efecto acumulativo, no planeado, de actividades de uso, acopio, descarte, reuso y redeposición de materiales diversos, repetidas durante los tres siglos considerados. Si bien la intervención antrópica en tales depósitos es indudable, su temporalidad y el grado de intencionalidad y formalismo involucrados varían (Brudenell y Cooper 2008; Morris y Jervis 2011; Garrow 2012). Cerámicas, fauna, huesos humanos, metalistería, sedimentos cenicientos o molinos de granito comparecen mayoritariamente como residuos manipulados en distintas etapas, resultantes de actividades previas cuyo contexto utilitario original ha quedado gravemente desfigurado. Pero ciertos materiales, utensilios completos o restos óseos articulados abandonados en hoyos o sobre los pavimentos de las cabañas, 
siguieron otro ciclo formativo: fueron depositados premeditadamente conforme a costumbres prescritas.

\subsection{Vasijas rotas: explorando la 'biografía cultural' de la cerámica}

La expresión 'biografía cultural' (Kopytoff 1986: 66-68) se viene empleando en sentido metafórico para caracterizar la transformación física y semántica de los objetos, desde su manufactura o 'nacimiento' y hasta su descarte final o 'muerte' (Gosden y Marshall 1999: 169-170; Jones 2002: 83-84; Joy 2009). La premisa de este enfoque es simple: al participar en interacciones sociales las cosas son dotadas de significados culturales y dichas connotaciones, lejos de ser estáticas, suelen cambiar con las circunstancias (Sterner 1989: 453; Gosden y Marshall 1999: 170; Jones 2002: 84). Esos sucesivos avatares pueden haber dejado huellas que permiten su reconocimiento arqueológico (Jones 2002: 86-102; Chapman y Gaydarska 2007: 130-142), pero también pueden haber conllevado transformaciones contextuales o de significado sin rastro físico (Gosden y Marshall 1999: 174; Immonen 2002: 28). El estudio biográfico de un objeto trata de identificar aquellos episodios de su itinerario de uso o 'vida social' que han dejado algún rastro legible. Se trata de reconstruir una narración discontinua y a menudo parcial, pero siempre enriquecedora, del ciclo de existencia de una cosa (Joy 2009).

El ya mencionado hoyo 23 del sector $\mathrm{V}$ de Pico Castro (Fig. 8) contenía un raro conjunto de vasijas cerámicas completas o semicompletas, algunas profusamente decoradas, que invitaba a ensayar una aproximación biográfica (Blanco González 2014).

Esta fosa era de perfil acampanado irregular, ensanchada en su fondo plano, con unos diámetros de $165 \mathrm{~cm}$ de boca y $185 \mathrm{~cm}$ de base por 75 $\mathrm{cm}$ de profundidad (Fig. 8C). Se colmató con dos niveles de arcillas, inicial y basal, y un lentejón ceniciento intercalado. Sobre su base se hallaron tres cazuelas troncocónicas con decoración metopada (Delibes de Castro et al. 2007: 121, fig. 8) (Fig. 8A) del tipo 9C de Rodríguez Marcos (2007: 344, fig. 199), con capacidades de entre 0,25 y 0,36 litros (Blasco Bosqued et al. 2007: 120, tab. 4). El vaso 1 (Fig. 8: A1 y A2) presenta metopas con zigzag verticales mediante incisiones y técnica de Boquique delimitadas por bandas excisas. Es un recipiente ejecutado con gran destreza, colocado completo e invertido junto a la pared oriental del pozo (Fig. 8C). En el extremo occidental de la fosa se halló el vaso 3, incompleto y también bocabajo (Fig. 8C). Este alterna metopas con posibles motivos astrales, soles y lunas (?), y zigzags horizontales (Fig. 8: A7 y A8). Entre otros cacharros parciales, se recuperaron varios trozos contiguos de una ollita ovoide incompleta de fondo plano y labio digitado (Fig. 8B) y una gran orza de $53 \mathrm{~cm}$ de alto y $24 \mathrm{~cm}$ de diámetro en la boca, que portaba ocho tetones y yacía recostada sobre su panza junto a la pared norte (Fig. 8C). Por último, diseminadas por el centro de la fosa y en torno a la orza (Fig. 8C) aparecieron varias porciones del vaso 2 que permiten recomponer gran parte de su mitad inferior y todo el borde continuo (Fig. 8: A6). Su perfil (Fig. 8: A5) es menos regular que el publicado (Delibes de Castro et al. 2007: 121, fig. 8) (Fig. 8: A4) y combina motivos ornamentales de las otras dos cazuelas: posibles 'soles' y espigas incisas junto a zigzags verticales excisos (Fig. 8: A4 y A5).

El rastreo minucioso de las marcas de uso, tafonomía y patrones de fragmentación y representación de estas vasijas ha procurado datos de interés sobre sus 'vidas sociales'. Los tres vasos troncocónicos fueron probablemente usados, como indican sus tiznes exteriores de hollín (Fig. 8: A2, A5, A8), también presentes al interior del 2 (Fig. 8: A6). La forma de romperse los cacharros ha resultado crucial en la comprensión del conjunto. El vaso 1 se abandonó completo y su rotura fue post-deposicional, natural e in situ, como consecuencia del peso soportado, ya que todos sus fragmentos - de tamaños homogéneos y sin lagunas- se recuperaron en conexión y exhiben fracturas frescas. En cambio los vasos 2 y 3 se rompieron en un momento pre-deposicional, fuera del hoyo y las porciones recuperadas -de tamaños considerables, que difícilmente habrían pasado desapercibidas- hubieron de ser recogidas e incluidas en él adrede. Esta hipótesis permite explicar sus lagunas: trozos ausentes que no han aparecido en el relleno del hoyo 23 ni en otras fosas excavadas en el sector V. Además pedazos contiguos de ambos recipientes muestran alteraciones dispares, adquiridas tras su rotura, pues abarcan fragmentos completos y alcanzan a las propias fracturas. En el reducido espacio del hoyo 

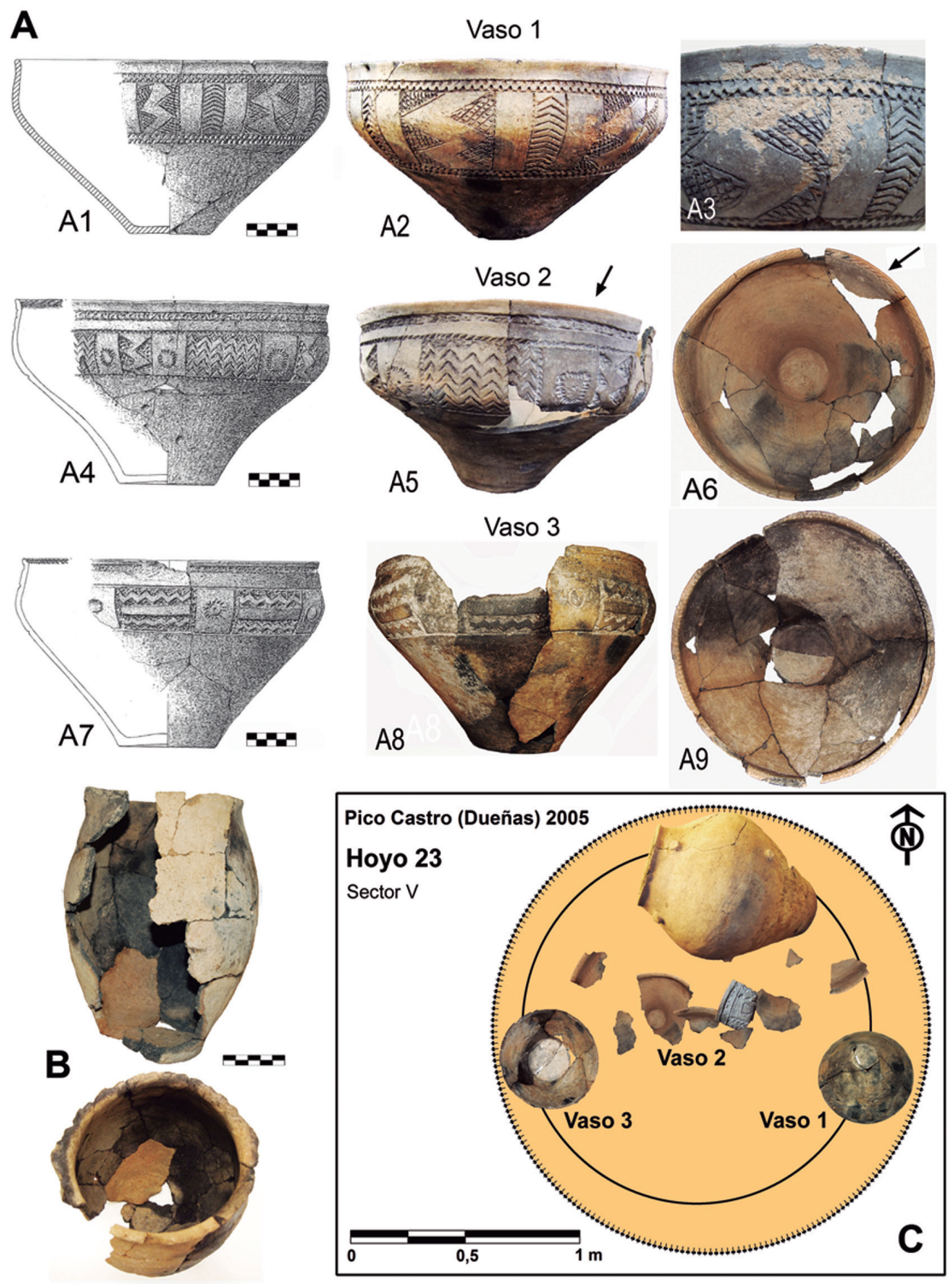

Fig. 8. Hoyo 23 de Pico Castro (Dueñas, Palencia) con materiales del final de Cogotas I: A. Cazuelas decoradas (las flechas señalan el fragmento quemado y concrecionado del vaso 2). B. Vistas lateral y cenital de la ollita ovoide con partes quemadas. C. Reconstrucción de los hallazgos en el nivel basal de la fosa. Escala en cm en A y B. Fotos A. Blanco; dibujos A1, A4 y A7, según Delibes de Castro et al. 2007: 121, fig. 8.

23 tales restos pudieron haber experimentado afecciones muy puntuales, tanto biológicas (actividad bacteriana, raíces) como químicas (cloruros, calcificaciones), algunas de ellas efectivamente reconocidas, como los desconchados por la acidez del sedimento (Fig. 8: A3) (C. Caple, J. Vuković com. pers.). Sin embargo, ciertos fragmentos también han revelado indicios de su paso por diversos estadios antes de su definitiva in- corporación al hoyo. El vaso 3 exhibe una inesperada y compleja biografía pos-rotura: partes intensamente erosionadas por meteorización o desgaste casan con otras frescas; trozos negruz$\cos$ y claros conciertan entre sí y se reconocen concreciones de diversas tonalidades (blancuzcas, amarillentas y rojizas) adheridas antes de incorporarse al hoyo (Fig. 8: A8 y A9). ¿Cómo acabaron juntos tales pedazos? Tras experimentar 
distintas afecciones, dichas porciones pudieron haber sido concertadas y adheridas con alguna sustancia desaparecida, como resina o brea (Elburg 2010: 6). Finalmente, la vasija así recompuesta pudo ser colocada invertida, emulando el intacto vaso 1 , de forma que al ser levantada por el arqueólogo dejó un 'flan de arena' moldeado (R. Martín Vela com. pers.). En el vaso 2 una única porción -precisamente aquella que comprende un soliforme y un zigzag - también exhibe una coloración externa más oscura (Fig. 8: A5 flecha) y una costra blanquecina interior (Fig. 8: A6 flecha). La exposición al fuego de ciertos trozos contiguos y su posterior recolección y deposición se confirma como una pauta característica, pues también se reconoce entre los fragmentos de la ollita ovoide recuperada en el mismo nivel basal (Fig. 8B). La rotura no significó el final de la 'vida social' de tales vasijas. Los fragmentos sufrieron nuevos avatares que han dejado rastro: se volvieron a usar, se desecharon o manipularon de forma dispar, resultando quemados varios de ellos. Por último, estas cerámicas, lejos de ser tratadas como basura inerte y desactivada, recibieron un abandono estipulado culturalmente: algunos trozos de la ollita ovoide y el vaso 2 fueron recolectados y arrojados a la fosa, mientras que el remendado vaso 3 y los intactos vaso 1 y la gran orza fueron delicadamente colocados allí.

El manejo de material cerámico fragmentario y su probable reunión y deposición selectiva en pozos también se verifica en campos de hoyos en la llanura. En 1998 se excavaron en el Cerro de la Cabeza (Ávila) (9) (Fig. 4B: 20) unas pocas y dispersas fosas correspondientes al final de Cogotas I en un extenso lugar, frecuentado entre el Neolítico y el Hierro Inicial (Fabián García et al. 2010). El hoyo 1 del cuadro 26-S, cuadrícula VII$\mathrm{E}$, contenía un relleno peculiar: 14 pellas de barro, 11 fragmentos óseos de fauna, 1 lasca de cristal de roca, 1 goterón metálico y 39 fragmentos cerámicos correspondientes a 10 recipientes. Uno de ellos pudo recomponerse salvo la base y, de nuevo, conforma una cazuela troncocónica de tipo 9C (Rodríguez Marcos 2007: 344) con una

(9) Sanz García, F. J. 1998: Trabajos Arqueológicos en la circunvalación de Ávila. Excavación Arqueológica en el Cerro de la Cabeza-Bascarrabal. Vol. I, pág. 39. Documento inédito consultable en el Servicio Territorial de Cultura de Ávila. cenefa excisa (Fig. 9). Lo peculiar del caso es que 14 de esos fragmentos componen una buena porción del recipiente y son de color negruzco, frente a la tonalidad clara de los 4 fragmentos contiguos (Fig. 9). Es inevitable relacionar el contenido de esta fosa-que parece acoger testimonios de distintas sustancias- con otra deposición extraordinaria en la misma cuadrícula: la fosa 1 del cuadro 27-R, que contenía un adolescente y una mujer joven con sendas pulseras broncíneas, caso único hasta hoy. Este enterramiento doble se había situado en un contexto ligeramente posterior (Fabián García et al. 2010), pero recientes dataciones $A M S$ de ambos individuos permiten ubicarlo con garantías en los últimos siglos de Cogotas I (A. Esparza, com. pers.).

Por último, en el ya mencionado sitio de $\mathrm{Mu}-$ cientes/San Lázaro (Fig. 4B: 10) se excavó en 2012 el hoyo UE 430, un depósito con abundante cerámica 'avanzada' junto a dos molinos de granito y un hacha plana de apéndices laterales (Aratikos 2012: 12-13, láms. 4-7). Esta fosa incluía varias vasijas incompletas que pudieron ser restituidas en diverso grado. Entre las mejor rehechas hay una urna bitroncocónica, una olla con digitaciones y parte de un borde de labio impreso cuyas porciones, aun concertando entre sí, presentan distinto grado de erosión, contrastes de color y pátinas diferentes (Aratikos 2012: lám. 5, nos. $5.1,5.2$ y 5.3 ).

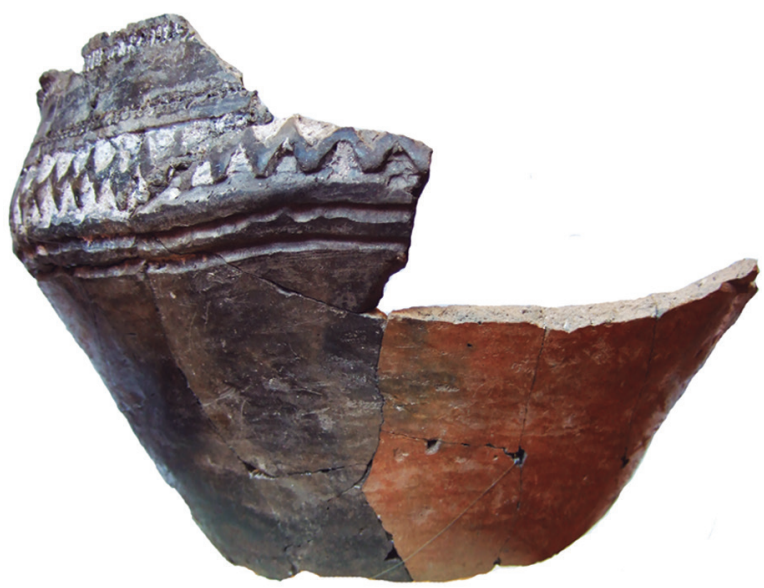

Fig. 9. Vasija excisa con pasta blanca del hoyo 1, cuadro 26-S, del Cerro de la Cabeza (Ávila). Obsérvese la diferente coloración entre las dos partes que casan. Final de Cogotas I. Diámetro: $26 \mathrm{~cm}$. Foto A. Blanco. 


\section{DISCUSIÓN}

Una vez examinada la evidencia material, señaladas sus limitaciones y presentadas algunas líneas de indagación iniciadas, es momento de reconsiderar la interpretación actual de dos temas clave sobre el final de Cogotas I: a) los repertorios cerámicos de 'plenitud' y 'avanzado' y b) la dualidad entre sitios encaramados y lugares del llano.

En el terreno del material cerámico nos enfrentamos a un panorama complejo. La tradición alfarera Cogotas I viene siendo pensada como una sucesión sustitutiva de 'subestilos' (Castro Martínez et al. 1995; Fernández-Posse 1998). Sin embargo, esa equiparación directa entre fases crono-culturales y repertorios cerámicos genera contradicciones. Según Fernández-Posse (1998: 100) "la secuencia y la cronología de Cogotas I están todavía lejos de ser cuestiones cerradas en tanto no se prescinda de ese desarrollo lineal de su cerámica". Hoy día, gracias a un empleo más riguroso y crítico del radiocarbono (Esparza Arroyo et al. 2012a) comenzamos a rebatir el esquema trifásico tradicional. Así, el reconocimiento de materiales propios de una fase póstuma, distinta y posterior a la etapa de 'plenitud' resulta discutible. La mezcla de materiales de 'plenitud' y 'avanzados', el empleo de los mismos recursos ornamentales y la ausencia de relaciones estratigráficas dificultan el deslinde de ambos repertorios alfareros (Quintana López y Cruz Sánchez 1996: 15-20; Rodríguez Marcos 2007: 373). Desde la novedosa perspectiva proporcionada por el $\mathrm{C} 14$, tales notas pudieran leerse en otro sentido: como prueba de la estrecha vinculación entre ambos elencos tipológicos, creados, usados y desechados por las mismas gentes. No faltan ejemplos etnohistóricos de contrastes en la cultura material que no responden a diferencias temporales ni a su distinta atribución étnica, sino a otras cuestiones. "Allí donde pueden reconocerse repertorios materiales solapados, es posible que éstos se relacionen no con distintos grupos de gente, sino con la misma gente haciendo cosas distintas en distintos momentos" (Thomas 1999: 121).

Alcanzar una comprensión más satisfactoria de la producción alfarera en el intervalo 1450$1150 \mathrm{cal} \mathrm{AC}$ en la Meseta requiere esbozar esos contextos de uso y abandono. Los datos aquí recopilados permiten avanzar algunos matices importantes: las vasijas de la 'plenitud' aparecen repartidas por todo el ámbito geográfico de Cogotas I (Fig. 4B), responden a un elenco tipológico variado (Rodríguez Marcos 2007: 338-349), conforme a unos códigos decorativos compartidos en territorios amplios (Abarquero Moras 2005) y no se reconocen patrones de descarte distintivos, con concentraciones diferenciales. Por contra, el repertorio 'avanzado' se define por unos perfiles más estandarizados y restrictivos (Delibes de Castro et al. 1990), ocasionalmente complejos -delicadas jarras, copas y cazuelas inestables, cuencos de bordes tan cerrados que merman su utilidad- y exhiben una decoración más singularizada o idiosincrática, representativa de regiones o incluso de sitios particulares. El análisis volumétrico de ciertos conjuntos de recipientes 'avanzados' depositados en hoyos, como los de la tumba 2 y el hoyo 12 de la Fábrica de Ladrillos (Blasco Bosqued et al. 2007: 117-123) refuerzan su interpretación como menaje para festines colectivos (Harrison 1995: 74; Abarquero Moras 2005: 56; Sánchez Polo 2012: 86). Además, tales vasijas parecen haberse abandonado solo en algunos pocos sitios (Fig. 4). Nuestro análisis biográfico se ha centrado en algunas de aspecto 'avanzado' desechadas en fosas, tanto en lugares en alto como en el llano. La comparación resulta pertinente al comprender contextos deposicionales equivalentes (Rosenwig 2009: 26; Garrow 2012: 90). Ello ha permitido reconocer secuencias de gestos similares entre la rotura de esos recipientes y su descarte definitivo, conllevando el quemado de ciertas porciones y su ulterior incorporación al mismo hoyo. Tales comportamientos cuadran bien con la expectativa de hallar prácticas ritualizadas entre estas sociedades (Blanco González 2011a).

En vista de todo ello, podría entenderse el elenco 'pleno' como el servicio utilitario cotidiano, elaborado, usado y desechado de forma menos protocolaria que la vajilla 'avanzada', cuyo énfasis ornamental parece asociado a unas prácticas de consumo y descarte más formal, posiblemente de tipo festivo y comunitario. Pero tal planteamiento reproduce un dualismo artificioso y torpe entre servicios domésticos/habituales versus ceremoniales/sacros (Immonen 2002), inoperante para interpretar Cogotas I. Los referidos gestos pautados de abandono no son exclusivos de la vajilla 'avanzada'; también afectan a recipientes de cocina y almacenaje como los de la 
fosa 23 de Pico Castro (Fig. 8B). Estas observaciones desaconsejan usar categorías excluyentes del tipo esotérico versus profano o extraordinario versus cotidiano para aproximarnos a dichas prácticas sociales. De momento, poco podemos aclarar lo que pudieron haber hecho las gentes del final de Cogotas I con ambos repertorios en diferentes contextos (Thomas 1999: 121).

Los epígrafes anteriores sugieren asimismo reconsiderar las restricciones de la documentación disponible a la hora de apoyar lecturas en clave socio-política. Cierta desigualdad social es intuida para este momento desde muy diversas perspectivas, como el historicismo cultural (Almagro-Gorbea 1986: 366-368), el funcionalismo (Delibes de Castro y Romero Carnicero 2011: 66; Arnáiz Alonso et al. 2012: 517-518) o el posprocesualismo (Sánchez Polo 2012: 86-87). Sin embargo, la dualidad del poblamiento, un argumento clave en tales interpretaciones, debe matizarse. En tal sentido se asemeja a la engañosa dicotomía entre recintos fosados y campos de hoyos sin foso del III milenio AC (Márquez Romero y Jiménez Jáimez 2010). El parecido entre los sitios en alto y aquellos en llano ha sido ya señalado (Díaz-delRío 2001: 296; Crespo Díez y Herrán Martínez 2012: 393) y aquí pueden añadirse otras observaciones a su favor.

En los sitios encumbrados se desarrollaron actividades cuyo rastro material puede confundirse con el de unos asentamientos populosos y sedentarios (Fernández-Posse 1998: 126-127; González-Tablas y Domínguez Calvo 2002: 71 y 226; Delibes de Castro et al. 2007: 122-123). Sin embargo, tres fuentes de incertidumbre nos llevan a reevaluar tales indicios: 1) la frecuente descontextualización de los hallazgos; 2) la desatención a su ciclo formativo, y 3) un probable sesgo cultural, que ya en época prehistórica hizo más visibles ciertos resultados imperecederos (Blanco González e.p.). Los riscos graníticos efectivamente acogieron cabañas, como las de Cancho Enamorado (López Jiménez y Martínez Calvo 2006), y en los sectores mejor abrigados de dichos promontorios habrá más casos (de momento se desconocen en las parameras calizas). Pero, siguiendo la tónica de la huella arqueológica de Cogotas I, las cabañas son excepcionales (Blanco González 2011b), y la función residencial no explica por sí sola la ocupación de tales lugares. Cancho Enamorado a 1.553 m.s.n.m. o Sanchorreja a 1.354 m.s.n.m. difícilmente serían habita- dos todo el año. Si estamos tratando con campos de hoyos en altura, entonces deben aplicarse las mismas cautelas interpretativas que a estos, evitándose toda estimación demográfica sobre su extensión total (Blasco Bosqued 2012: 190-191). Unas dinámicas de ocupación de carácter episódico, basadas en el descarte masivo de restos de manera repetida, emergen como principios más plausibles que expliquen su génesis. Parecidas precauciones deben contemplarse al tratar la gama de actividades artesanales reconocidas en tales sitios (Delibes de Castro et al. 1995: 56; Delibes de Castro et al. 2007: 120-123). Así, la reunión de bloques graníticos en Carricastro se ha enarbolado como prueba de la confección in situ de molinos de ese material alóctono (Delibes de Castro et al. 2007: 123), pero poco sabemos de su contexto arqueológico (Crespo Díez y Herrán Martínez 2012: 380). De la notable acumulación de molinos de granito en la superficie de la Mesa de Carpio (Cruz Sánchez 2006/7) no se colige la existencia de unos talleres de procesado de cereal a una escala supradoméstica (Lull et al. 2010: 19-24). Esa misma imagen -de prospección superficial- podría deberse a la remoción reciente de piezas reunidas allí a lo largo del tiempo y amortizadas individualmente en fosas (Blasco Bosqued et al. 2007: 45) o reusadas en bancales o terraplenes prehistóricos. Las pruebas de actividad metalúrgica ilustran muy bien este problema: se conocen goterones y subproductos de fundición en La Mesa de Carpio (Cruz Sánchez 1997: 269) o Carricastro (Delibes de Castro et al. 2007: 122; Crespo Díez y Herrán Martínez 2012: 381) e incluso moldes para fundir tipos vernáculos (hachas planas, puñales) junto a productos atlánticos (lanzas tubulares) en Carricastro y en otros sitios en llanura, como Piedrahita (Delibes de Castro et al. 2007: 122; Arnáiz Alonso et al. 2012: 512-514). Pero nada sabemos de los obradores. Los únicos contextos bien documentados arqueológicamente para el trabajo metalúrgico son, una vez más, las fosas (Fraile Vicente y Cruz Sánchez 2012). En suma, las huellas de tales artesanías consisten en residuos secundarios, bien redepositados inadvertidamente o bien, como comenzamos a corroborar con más datos, incorporados de forma deliberada a la fracción de restos conservados. Su visibilidad en el registro material parece responder a la voluntad de remarcar esos quehaceres, tal vez en relación con la muerte de quienes los desempeñaron (Sánchez 
Polo 2012: 86). Se reconocen además gestos ritualizados similares en el descarte de ciertas vasijas, tanto en sitios elevados como de planicie. Es el caso de la colocación invertida de cazuelas con decoración 'avanzada' en el Fondo 12 de la Fábrica de Ladrillos (Blasco Bosqued et al. 2007: 194 y 240-242) y en el hoyo 23 de Pico Castro. Las cerámicas presentadas aquí sugieren incluso unas inusitadas secuencias de gestos reglamentados, con resultados premeditados y diferidos en los que intervino el fuego.

Los lugares encumbrados pudieran adquirir mayor sentido a la luz de otros casos coetáneos conocidos en la mitad septentrional peninsular. En todos ellos destaca la fisonomía elegida: montes isla en el dominio granítico (Fig. 5A y B) o lenguas de páramo y cerros testigo entre las estructuras tabulares sedimentarias (Fig. 5C y D). Sus condiciones defensivas resultan dudosas ante escarceos entre grupos poco numerosos. La visibilidad desde ellos es variada y su alcance y efectividad real inverificables. Nunca falta en tales sitios su prominencia como referente visual a media y larga distancia, y sobre todo la presencia de superficies elevadas bien definidas. Al respecto, conviene subrayar ahora algunas particularidades. En Sanchorreja encontramos dentro del primer recinto un espacio restringido al punto más alto de la plataforma superior (GonzálezTablas y Domínguez Calvo 2002: 47-51) demarcado por la vieja cerca erigida en el Bronce Antiguo (González-Tablas y Domínguez Calvo 2002: 226). Algo parecido se rastrea en la Casa del Santo, en la cima del Cerro del Berrueco (Fig. 6C), donde se deslindó un área cerrada por un parapeto de piedra "lo suficientemente alto como para ocultar de la vista el ámbito así delimitado y segregado" (10). Así pues, en ambos sitios se eligieron plataformas planas en los puntos más elevados, demarcándose allí unos "espacios segregados, vinculados a nociones de secretismo y acceso privilegiado" (Armada Pita 2008: 144; cf. González Ruibal 2006/07: 113), donde comienzan a depositarse los primeros calderos de remaches de tipología atlántica (Armada Pita 2008: 130-154) o sus inmediatos precedentes: los fragmentos de chapa de bronce de Pico Castro (11) y Carricastro (Delibes de Castro et al. 2007:

(10) López Jiménez 2003, pág. 31 en nota 2.

(11) Crespo Martín et al. 2005a, pág. 47 en nota 3.
123, fig. 10; Herrán Martínez 2008: 161 y 520, fig. 108). Objetos como asadores y calderos, algunos importados de remotos lugares, portadores de extensas 'biografías' (Armada 2008), podrían haber sido regalados o intercambiados allí. Productos vernáculos como los puñales de remaches y las hachas planas, asiduamente recuperados en tales promontorios (Cruz Sánchez 1997), invitan a ser comprendidos como símbolos de alianzas o dones circulantes mediante relaciones de intercambio social (Arnáiz Alonso et al. 2012: 514518), y no solo como indicio de unas elites y su ideología marcial (Cruz Sánchez 1997). González Ruibal (2006/07: 103-113) propuso que tales lugares monumentalizados, frecuentados ininterrumpidamente, pudieron ser referentes paisajísticos sacros y míticos, vinculados con los antepasados. En el Bronce Final inglés, R. Bradley (2007: 232-235) ha interpretado ciertos lugares en alto con grandes muladares y abundantes restos faunísticos y de producción artesanal broncística y textil como focos para una población amplia, reunida allí durante fiestas periódicas para intercambiar bienes y elaborar objetos. Los casos de Cogotas I aducidos podrían pues constituir el precedente de otros palcos escenográficos del siglo VIII AC asociados a banquetes comunitarios de carne y sustancias psicoactivas, conllevando la rotura y deposición de metalurgia exótica (Armada Pita 2008, 2011). Lo testimonia la acrópolis de Chao Samartín (Villa Valdés y Cabo Pérez 2003; Villa Valdés 2010) fuera del ámbito cogoteño, o la propia reutilización de Sanchorreja y su 'sector necrópolis' durante el Hierro Inicial, donde se concentran centenares de trozos de toréutica atlántica y mediterránea (González-Tablas 1990). Atendiendo a tal cúmulo de evidencias, los lugares encaramados del final de Cogotas I podrían haber sido una prolongación de los sitios 'amurallados' de la fase Protocogotas, unos 'hitos visibles de cohesión, agregación grupal o identidad colectiva' (Díaz-del-Río 2001: 297) donde habrían convivido diversas comunidades durante fechas señaladas (Rodríguez Marcos 2007: 427 y 430). Tales reuniones festivas habrían consistido en la celebración de banquetes, la manufactura de artesanías y el intercambio de bienes, personas y animales.

Dichas sedes, sobre hitos destacados del paisaje, serían campos de hoyos a mayor altitud que el resto, dispersos presidiendo física y simbólicamente el discurrir cotidiano en derredor 
(Fig. 4B). Los restos domésticos encontrados en ellas pudieran compadecerse con el concepto de 'poblado sucedáneo o de sustitución' (Bernardini 2004: 335): sitios mantenidos por grupos dispersos, con el ánimo de simbolizar la idea de la comunidad ausente (Márquez Romero y Jiménez Jáimez 2010: 511). La frecuencia de restos previos en los promontorios ocupados durante el Bronce Final y su propia perdurabilidad y visibilidad respaldarían su papel como sedes ancestrales, sostén de relatos cosmológicos e identidades (González Ruibal 2006/07: 102-112). Antes que poblados estables serían nodos alrededor de los cuales gravitarían los grupos locales: "los encuentros suelen ser los momentos más oportunos para renovar, subrogar o modificar efectivamente los límites del paisaje, las relaciones sociales y los derechos de acceso sobre los recursos" (Márquez Romero y Jiménez Jáimez 2010: 488). Esta línea interpretativa se adecúa bien al hipotético funcionamiento sociológico de las comunidades meseteñas: unidades familiares de carácter efímero, abocadas a su disolución a la muerte del progenitor, concluyendo con ello las alianzas, prerrogativas y derechos de sus miembros (Blanco González 2011b: 402-404). Precisamente el repertorio de Cogotas I 'avanzado' pudo emplearse de forma análoga a como J. Thomas (2010: 1) ha concebido el papel de la Grooved Ware en el III milenio AC, como "el medio para construir nuevas formas de afinidad colectiva". De hecho, los contextos en que se empleó la cerámica 'avanzada' de Cogotas I contribuirían a modelar o reforzar esos vínculos identitarios inestables. Ciertas vasijas pudieron elaborarse con motivo de las referidas fiestas, y su decoración parece enfatizar las raíces comunes de los grupos involucrados (Blanco González 2011a: 134-137): empleando pasta blanca y motivos campaniformes y emulando el Boquique de las alfarerías neolíticas "con tintes de "revival', o de regreso a patrones en gran medida perdidos" (Delibes de Castro et al. 1990: 86).

\section{CONCLUSIÓN}

El principal objetivo del trabajo ha consistido en reclamar una mayor atención sobre las limitaciones inherentes a la evidencia arqueológica como requisito previo a cualquier inferencia funcional o social. Para ello se han explorado dos líneas de trabajo novedosas: a) el ciclo formativo de los contextos deposicionales (Jiménez Jáimez 2008), caracterizando los ritmos y dinámicas de acumulación de los desechos y b) la 'biografía cultural' (Kopytoff 1986) del material cerámico, atendiendo a su grado de fragmentación, erosión y representación. Ambos enfoques han proporcionado unas bases preliminares para releer de forma crítica el final de Cogotas I (1450-1150 cal AC) en la Meseta. En este artículo no se ha pretendido rebatir las lecturas socio-políticas formuladas, sino llamar la atención sobre su inadecuado engranaje con el tipo de evidencia aducida hasta ahora en su apoyo. El volumen de restos encontrado en los lugares elevados o su carácter doméstico o artesanal no pueden alegarse como indicios claros de unos procesos de concentración poblacional permanente (contra Fernández-Posse 1998: 126-127; González-Tablas y Domínguez Calvo 2002: 226; Delibes de Castro et al. 2007: 122) o como prueba de una acusada intensificación y especialización productivas (contra Fernández-Posse 1998: 137-140; Celis Sánchez 2002: 100-101; Cruz Sánchez 2006/7: 113-116; Delibes de Castro et al. 2007: 120-123). El acopio de residuos de actividades recientes, junto a la remoción de otros desechos previos, y su mezcla y redeposición a veces selectiva y premeditada, configuraron las principales dinámicas formativas de un registro material sesgado ya desde hace 3.000 años. Cualquier lectura arqueológica debería considerar tales interferencias antes de pronunciarse sobre cuestiones de mayor calado teórico.

La evidencia material de Cogotas I tiene mayor potencial informativo sobre otro tipo de acciones del pasado: las referidas al uso y gestión de los desechos encontrados (Blanco González e.p.). Aquí se ha sugerido la hipótesis de encontrarnos ante unos ciclos de uso y descarte distintivos para los repertorios cerámicos 'plenos' y 'avanzados'. Sin embargo, tanto las vasijas como los sitios de la época no encajan en clasificaciones dualistas y simplificadoras del tipo ceremonial/sacro versus ordinario/profano o central versus subordinado. Es necesario evaluar el grado de formalismo y voluntad en el abandono de los restos en diversos contextos deposicionales. Ello será posible caracterizando sus 'historias deposicionales' (Brudenell y Cooper 2008; Garrow 2012), así como caracterizando las 'biografías culturales' de los materiales allí incorporados 
(Kopytoff 1986; Gosden y Marshall 1999). En las sedes agregativas encaramadas, y posiblemente también en el llano, se hallarán depósitos voluminosos de restos domésticos (fauna consumida, desechos de artesanías estimadas socialmente, restos de vasijas vinculadas a episodios o seres) descartados de manera simultánea, producto de reuniones festivas multitudinarias. Se requieren estudios científicos de la cerámica, que ayuden a caracterizar las conjeturas aquí esbozadas sobre el empleo de ciertas vasijas en tales rituales. Resultaría muy revelador reconocer pautas selectivas de vertido. La exclusiva incorporación de trozos colindantes del borde o la base de recipientes rotos, en ocasiones con diversas trayectorias pos-rotura, podría ser un buen indicador de cierta premeditación en las maneras de abandonarlos. Pero, mayoritariamente, la evidencia parece fruto de unas prácticas de descarte rutinarias y despreocupadas, sin pretensión explícita de deshacerse de los desechos según reglas tan estrictas. Su más precisa definición permitirá comprender mejor tales hábitos consuetudinarios (Garrow 2012) entre las sociedades aquí estudiadas.

\section{AGRADECIMIENTOS}

Trabajo realizado dentro del proyecto posdoctoral Past Fragments financiado por la Comisión Europea (Marie Curie Intra-European Fellowship 298285) y enmarcado en el programa de investigación "Nuevos hallazgos y nuevas perspectivas en el estudio de los restos humanos del grupo Cogotas I" (HAR 2009-10105 Ministerio de Ciencia e Innovación, Investigador Principal Á. Esparza). M. Crespo (codirector de la intervención en Pico Castro) y R. Martín Vela (excavador del hoyo 23 del mismo) me proporcionaron documentación e informaciones para interpretar ese hallazgo. El personal de los museos de Palencia y Ávila me facilitó el estudio de los materiales referidos. Á. Palomino Lázaro, Ó. López Jiménez y J. Sanz García me procuraron documentación de sus respectivas excavaciones. P. Díaz-del-Río, L. García Sanjuán, Á. Esparza, J. A. Rodríguez Marcos y un evaluador anónimo leyeron el borrador inicial y contribuyeron a mejorarlo con sus sugerencias y críticas.

\section{BIBLIOGRAFÍA}

Abarquero Moras, F. J. 2005: Cogotas I. La difusión de un tipo cerámico durante la Edad del Bronce. Junta de Castilla y León. Valladolid.

Abarquero Moras, F. J. y Delibes de Castro, G. 2009: "La posición cronológica del yacimiento prehistórico de 'El Pelambre': apreciaciones tipológicas y dataciones absolutas". En M. L. González Fernández (ed.): 'El Pelambre' Villaornate, León. El horizonte Cogotas I de la Edad del Bronce y el periodo tardoantiguo en el valle medio del Esla. Tragsa. Madrid: 197-213.

Almagro-Gorbea, M. 1986: "El Bronce Final y la Edad del Hierro. La formación de las etnias y culturas prerromanas". En F. Jordá, M. Pellicer, P. Acosta y M. Almagro-Gorbea: Historia de España 1. Prehistoria. Gredos. Madrid: 341-532.

Almagro-Gorbea, M. y Fernández-Galiano, D. 1980: Excavaciones en el Cerro de Ecce Homo (Alcalá de Henares, Madrid). Diputación Provincial de Madrid. Madrid.

Aratikos S. L. 2012: Trabajos de excavación de sondeos arqueológicos en el yacimiento MucientesSan Lázaro (Castronuño, Valladolid). Valladolid. http://www.aratikos.com/docftp/2012 - Excavacion en yacimiento Mucientes-San Lazaro en Castronu $\% \mathrm{C} 3 \% 83 \% \overline{\mathrm{C}} 2 \% \mathrm{~B} 10$-Valladolid.pdf (consulta 4-VII-2014).

Armada Pita, X. L. 2008: “¿Carne, drogas o alcohol? Calderos y banquetes en el Bronce Final de la Península Ibérica". Cuadernos de Prehistoria y Arqueología de la Universidad de Granada 18: 125-162.

Armada Pita, X. L. 2011: "Feasting Metals and the Ideology of Power in the Late Bronze Age of Atlantic Iberia". En G. Aranda, S. Montón-Subías y M. Sánchez Romero (eds.): Guess Who's Coming to Dinner. Feasting Rituals in the Prehistoric Societies of Europe and the Near East. Oxbow Books. Oxford: 158-183.

Arnáiz Alonso, M. A.; Carmona, E. y Montero, J. 2012: "Bienes competitivos-no competitivos: la función de los metales en Cogotas I". En J. A. Rodríguez Marcos y J. Fernández Manzano (eds.): Cogotas I: una cultura de la Edad del Bronce en la Península Ibérica. Universidad de Valladolid. Valladolid: 509-522.

Barril Vicente, M. 1995: “El Castro de 'Los Baraones' (Valdegama, Palencia): un poblado en el alto valle del Pisuerga". En F. Burillo (ed.): Poblamiento Celtibérico. III Simposio sobre los Celtíberos. Institución "Fernando el Católico". Zaragoza: 399-408.

Barroso Bermejo, R. M. 2002: El Bronce Final y los comienzos de la Edad del Hierro en el Tajo

Trab. prehist., 71, N. ${ }^{\circ} 2$, julio-diciembre 2014, pp. 305-329, ISSN: 0082-5638 doi: $10.3989 /$ tp.2014.12136 
superior: (Prehistoria I). Universidad de Alcalá de Henares. Madrid.

Bellido Blanco, A. 2012: "Propuesta de interpretación de unas estructuras de combustión y sus concomitancias”. En J. A. Rodríguez Marcos y J. Fernández Manzano (eds.): Cogotas I: una cultura de la Edad del Bronce en la Península Ibérica. Universidad de Valladolid. Valladolid: 469-481.

Bernardini, W. 2004: "Hopewell geometric earthworks: a case study in the referential and experiential meaning of monuments". Journal of Anthropological Archaeology 23: 331-356.

Blanco González, A. 2011a: "Práctica social, memoria y ritual en Cogotas I. Esbozo teórico para un enfoque renovado". Trabajos de Prehistoria 68 (1): 123-146.

Blanco González, A. 2011b: "From huts to 'the house'. The shift in perceiving home between the Bronze Age and the Early Iron Age in Central Iberia (Spain)". Oxford Journal of Archaeology 30 (4): 393-410.

Blanco González, A. 2014: “Tracking the social lives of things. Biographical insights into Bronze Age pottery in Spain". Antiquity 88 (340): 441-455.

Blanco González, A. en prensa: "Unconventional prehistoric worlds: untangling the Later Bronze Age in Central Iberia". Cambridge Archaeological Journal.

Blasco Bosqued, M. C. 2012: “Cogotas I en la Meseta española”. En J. A. Rodríguez Marcos y J. Fernández Manzano (eds.): Cogotas I: una cultura de la Edad del Bronce en la Península Ibérica. Universidad de Valladolid. Valladolid: 187-218.

Blasco Bosqued, M. C. y Lucas Pellicer, M. R. 2002: "El Bronce Medio y Final: el horizonte Cogotas I y la secuencia Protocogotas-Cogotas I en la Colección Bento: tradición y renovación". En M. C. Blasco (ed.): La Colección Bento del Museu d'Arqueologia de Catalunya. Una nueva mirada a la Prehistoria de Madrid. Museu d'Arqueologia de Catalunya. Barcelona: 195-225.

Blasco Bosqued, M. C.; Blanco, J. F.; Liesau, C.; Carrión, E.; Baena, J. S.; Quero, S.; Rodríguez de La Esperanza, M. J. y García, J. 2007: El Bronce medio y Final en la región de Madrid. El poblado de la Fábrica de Ladrillos (Getafe, Madrid). Ayuntamiento de Madrid. Madrid.

Bradley, R. 2007: The Prehistory of Britain and Ireland. Cambridge University Press. Cambridge.

Brudenell, M. y Cooper, A. 2008: "Post-middenism. Depositional histories on Later Bronze Age settlements at Broom, Bedfordshire". Oxford Journal of Archaeology 27 (1): 15-36.

Cabré Aguiló, J. 1929: "Cerámica de la segunda mitad de la época del Bronce en la Península Ibérica". Actas y Memorias de la Sociedad Española de An- tropología, Etnografia y Prehistoria VIII, LXXII, 58: 205-245.

Calleja González, M. V. 1975: "Un yacimiento de la primera Edad del Hierro en Dueñas (Palencia)". Sautuola I: 161-168.

Castro Martínez, P. V.; González, P.; Lull, V. y Micó, R. 1996: Cronología de la Prehistoria Reciente en la Península Ibérica y Baleares (c. 2800-900 cal $A N E$ ). British Archaeological Reports, International Series 652, Archaeopress. Oxford.

Castro Martínez, P. V.; Micó, R. y Sanahuja, M. E. 1995: "Genealogía y cronología de la Cultura Cogotas I (El estilo cerámico y el grupo de Cogotas I en su contexto arqueológico)". Boletín del Seminario de Estudios de Arte y Arqueología 61: 51-118.

Celis Sánchez, J. 2002: "El Bronce Final y la primera Edad del Hierro en el noroeste de la Meseta". En M. A. de Blas y A. Villa (eds.): Los poblados fortificados del Noroeste de la Península Ibérica: Formación y desarrollo de la Cultura Castreña. Ayuntamiento de Navia. Navia: 97-125.

Celis Sánchez, J. 2007: "El contexto cultural del depósito de Valdevimbre. El Bronce Final en el noroeste de la Meseta". En J. Celis, G. Delibes de Castro, J. Fernández Manzano y L. Grau (eds.): El hallazgo leonés de Valdevimbre y los depósitos del Bronce Final Atlántico en la Península Ibérica. Junta de Castilla y León y Diputación de León. Salamanca: 132-167.

Celis Sánchez, J.; Delibes, G.; Fernández, J; Grau, L.; Hernández, M.; Herrán, J. I. y Rovira, S. 2007: "Consideración final: el depósito de Valdevimbre y la sociedad Cogotas I". En J. Celis, G. Delibes de Castro, J. Fernández Manzano y L. Grau (eds.): El hallazgo leonés de Valdevimbre y los depósitos del Bronce Final Atlántico en la Península Ibérica. Junta de Castilla y León y Diputación de León. Salamanca: 168-175.

Crespo Díez, M. y Herrán Martínez, J. I. 2012: “Primera intervención arqueológica en el yacimiento de la Edad del Bronce de Carricastro (Tordesillas, Valladolid)". En J. A. Rodríguez Marcos y J. Fernández Manzano (eds.): Cogotas I: una cultura de la Edad del Bronce en la Península Ibérica. Universidad de Valladolid. Valladolid: 377-395.

Cruz Sánchez, P. J. 1997: "Nuevos puñales de remaches de bronce procedentes de la Mesa de Carpio (Villagonzalo de Tormes, Salamanca)". Zephyrus 50: 263-272.

Cruz Sánchez, P. J. 2006/7: "La organización socioeconómica de la Mesa de Carpio y su entorno (Villagonzalo de Tormes, Salamanca) a través de los artefactos macrolíticos pulimentados". Boletín del Seminario de Estudios de Arte y Arqueología 7273: $93-121$. 
Chapman, J. y Gaydarska, B. 2007: Parts and Wholes. Fragmentation in prehistoric context. Oxbow. Oxford.

Delibes de Castro, G. 1978: "Una inhumación triple de facies Cogotas I en San Román de Hornija (Valladolid)". Trabajos de Prehistoria 35: 225-250.

Delibes de Castro, G.; Fernández, J. y Herrán, J. I. 2007: "Los Bronces de Valdevimbre y la metalurgia Cogotas I". En J. Celis, G. Delibes de Castro, J. Fernández Manzano y L. Grau (eds.): El hallazgo leonés de Valdevimbre y los depósitos del Bronce Final Atlántico en la Península Ibérica. Junta de Castilla y León y Diputación de León. Salamanca: 106-131.

Delibes de Castro, G.; Fernández, J. y Rodríguez, J. A. 1990: "Cerámica de plenitud de Cogotas I: el yacimiento de San Román de la Hornija (Valladolid)". Boletín del Seminario de Estudios de Arte y Arqueología 56: 64-105.

Delibes de Castro, G. y Fernández-Miranda, M. 1986/87: "Aproximación a la cronología del Grupo Cogotas I". Zephyrus 39-40: 17-30.

Delibes de Castro, G. y Pérez Rodríguez, F. J. 2002: "Prehistoria de Palencia". En P. Colmenares (ed.): Historia de Palencia. De la Prehistoria a la Época Medieval. Vol. I. Palencia: 13-67.

Delibes de Castro, G. y Romero Carnicero, F. 2011: "La plena colonización agraria del Valle Medio del Duero". Complutum 22 (2): 49-94.

Delibes de Castro, G.; Romero, F.; Sanz, C.; Escudero, Z. y San Miguel, L.C. 1995: "Panorama arqueológico de la Edad del Hierro en el Duero medio". En G. Delibes, F. Romero y A. Morales (eds.): Arqueología y Medio Ambiente. El primer milenio a.C. en el Duero medio. Junta de Castilla y León. Valladolid: 49-146.

Díaz-del-Río, P. 2001: La Formación del Paisaje Agrario: Madrid en el III y II milenios BC. Comunidad de Madrid. Madrid.

Díaz Santana, B. 1999: "Contactos precoloniales durante el Bronce Final en el occidente peninsular: el papel activo de las comunidades indígenas". $G a$ llaecia 18: 137-155.

Elburg, R. 2010: "A Neolithic Treasure Chest". The European Archaeologist 33: 4-6.

Esparza Arroyo, A. 2009: "Recuperando el tiempo perdido". Trabajos de Prehistoria 66 (1): 185-187.

Esparza Arroyo, A.; Velasco, J. y Delibes, G. 2012a: "HUM 2005-00139: Planteamiento y primeros resultados de un proyecto de investigación sobre la muerte en Cogotas I'. En J. A. Rodríguez Marcos y J. Fernández Manzano (eds.): Cogotas I: una cultura de la Edad del Bronce en la Península Ibérica. Universidad de Valladolid. Valladolid: 259-320.

Esparza Arroyo, A.; Velasco, J. y Delibes, G. 2012b: "Exposición de cadáveres en el yacimiento de Tordillos (Aldeaseca de la Frontera, Salamanca). Pers- pectiva bioarqueológica y posibles implicaciones para el estudio del ritual funerario de Cogotas I". Zephyrus 59 (1): 95-128.

Fabián García, J. F. 2012: "Proto-Cogotas I en el suroeste de la Meseta Norte". En J. A. Rodríguez Marcos y J. Fernández Manzano (eds.): Cogotas I: una cultura de la Edad del Bronce en la Península Ibérica. Universidad de Valladolid. Valladolid: 323-348.

Fabián García, J. F.; Strato y Blanco González, A. 2010: "El enterramiento en fosa del Cerro de la Cabeza (Ávila). La cuestión funeraria en el Bronce Final / Hierro I en el sur-oeste de la Meseta Norte". En P. Bueno, A. Gilman, C. Martín y J. Sánchez Palencia (eds.): Arqueología, Sociedad, Territorio y Paisaje. Homenaje a María Dolores FernándezPosse. Bibliotheca Praehistorica Hispana XXVIII, CSIC. Madrid: 183-194.

Fernández Gómez, F. 1995: “La Edad del Hierro”. En M. Mariné (ed.): Historia de Ávila. I. Prehistoria e Historia Antigua. Institución Gran Duque de Alba, Diputación Provincial de Ávila. Ávila: 105-269.

Fernández Manzano, J. 1986: Bronce Final en la Meseta Norte española: el utillaje metálico. Junta de Castilla y León. Valladolid.

Fernández Manzano, J. y Palomino Lázaro, A. L. 1992: "Cogotas I en Tierra de Campos: el yacimiento de Pórragos en Bolaños (Valladolid)". Boletín del Seminario de Estudios de Arte y Arqueología 57: 63-73.

Fernández-Posse, M. a D. 1986: "La Cultura de Cogotas I". En O. Arteaga (ed.): Homenaje a Luis Siret (1934-1984), Cuevas de Almanzora, Sevilla. Junta de Andalucía. Sevilla: 475-487.

Fernández-Posse, M. ․ D. 1986/87: “La cerámica decorada de Cogotas I". Zephyrus 39-40: 231-237.

Fernández-Posse, M. ${ }^{a}$ D. 1998: La investigación protohistórica en la Meseta y Galicia. Síntesis. Madrid.

Fraile Vicente, A. y Cruz Sánchez, P. J. 2012: “Apuntes sobre la metalurgia de Cogotas I en el valle medio del Duero: a propósito del molde de fundición de Soto de Tovilla (Tudela de Duero, Valladolid)". En J. A. Rodríguez Marcos y J. Fernández Manzano (eds.): Cogotas I: una cultura de la Edad del Bronce en la Península Ibérica. Universidad de Valladolid. Valladolid: 483-495.

Galán Saulnier, C. 1998: "Sobre la cronología de Cogotas I...". Cuadernos de Prehistoria y Arqueología de la Universidad Autónoma de Madrid 25: 201-243.

Garrow, D. 2012: "Odd deposits and average practice: a critical history of the concept of structured deposition". Archaeological Dialogues 19 (2): 85-115.

González Ruibal, A. 2006/07: Galaicos. Poder y comunidad en el Noroeste de la Península Ibérica (1200 a.C.-50 d.C.). Tomo I. Museo Arqueolóxico e Histórico. A Coruña. 
González-Tablas, F. J. 1990: La necrópolis de 'Los Castillejos' de Sanchorreja. Universidad de Salamanca. Salamanca.

González-Tablas, F. J. y Domínguez Calvo, A. 2002: Los Castillejos de Sanchorreja (Ávila): campañas de 1981, 1982 y 1985. Universidad de Salamanca. Salamanca.

Gosden, C. y Marshall, Y. 1999: "The cultural biography of objects". World Archaeology 31 (2): 169178.

Harrison, R. J. 1995: Bronze Age expansion 1750$1250 \mathrm{BC}$ : the Cogotas I phase in the Middle Ebro Valley. Veleia 12: 67-77.

Herrán Martínez, J. I. 2008: Arqueometalurgia de la Edad del Bronce en Castilla y León. Universidad de Valladolid. Valladolid.

Iniesta Ayerra, J. 2006: Materiales Cogotas I procedentes del Caserío de Perales. Universidad Autónoma de Madrid. Madrid.

Immonen, V. 2002: "Functional Ladles or Ceremonial Cutlery? A Cultural Biography of Prehistoric Wooden Spoons from Finland". Acta Borealia 19 (1): 27-47.

Jiménez Jáimez, V. 2008: "El ciclo formativo del registro arqueológico. Una alternativa a la dicotomía deposicional/posdeposicional". Zephyrus 62 (2): 125-137.

Jones, A. 2002: Archaeological Theory and Scientific Practice. Cambridge University Press. Cambridge.

Joy, J. 2009: "Reinvigorating object biography: reproducing the drama of objects lives". World Archaeology 41 (4): 540-56.

Kopytoff, I. 1986: "The cultural biography of things: commoditization as process". En A. Appadurai (ed.): The Social Life of Things: Commodities in Cultural Perspective. Cambridge University Press. Cambridge: 64-91.

López Jiménez, O. y Martínez Calvo, M. ${ }^{\mathrm{a}}$ V. 2006: "El proyecto Zona Arqueológica del Cerro de El Berrueco". Arqueoweb 8 (1). http://www.ucm.es/ info/arqueoweb/pdf/8-1/lopez.pdf (consulta 11-VII2014).

Lucas, G. 2012: Understanding the Archaeological Record. Cambridge University Press. Cambridge.

Lull, V.; Micó, R.; Rihuete, C. y Risch, R. 2010: "Las relaciones políticas y económicas de El Argar”. Menga 1: 11-35.

Maluquer de Motes, J. 1958a: El castro de Los Castillejos de Sanchorreja. Universidad de Salamanca. Salamanca.

Maluquer de Motes, J. 1958b: Excavaciones arqueológica en el Cerro del Berrueco. Universidad de Salamanca. Salamanca.

Márquez Romero, J. E. y Jiménez Jáimez, V. 2010: Recintos de Fosos. Genealogía y significado de una tradición en la Prehistoria del suroeste de la
Península Ibérica (IV-III milenios AC). Junta de Andalucía. Málaga.

Martín Valls, R. y Delibes de Castro, G. 1972: "Nuevos yacimientos de la primera Edad del Hierro en la Meseta Norte". Boletín del Seminario de Estudios de Arte y Arqueología 38: 5-54.

Martín Valls, R. y Delibes de Castro, G. 1973: "Recientes hallazgos cerámicos de la fase Cogotas I en la provincia de Salamanca". Boletín del Seminario de Estudios de Arte y Arqueología 39: 395-402.

Martín Valls, R. y Delibes de Castro, G. 1976: "Sobre la cerámica de la fase Cogotas I". Boletín del Seminario de Estudios de Arte y Arqueología 42: 5-18.

Mederos Martín, A. 2012: "El final de Cogotas I y los inicios de la Edad del Hierro en el centro de la Península Ibérica (1200-800 AC)". En J. Morín y D. Urbina (eds.): El primer milenio a.C. en la Meseta Central. De la longhouse al oppidum 1. Primera Edad del Hierro. Auditores de Energía y Medio Ambiente. Madrid: 73-107.

Méndez Madariaga, A. 1994: "La Edad del Bronce en Guadalajara: una visión de conjunto". En La Edad del Bronce en Castilla-La Mancha. Actas del Simposio (Toledo 1990). Diputación Provincial de Toledo. Toledo: 111-144.

Méndez Madariaga, A. y Velasco Steigrad, F. 1984: "La Muela de Alarilla. Un yacimiento de la Edad del Bronce en el valle medio del río Henares". Revista de Arqueología 37: 6-16.

Misiego, J. C.; Sanz, F. J.; Marcos, G. J. y Martín, M. A. 1999: "Excavaciones Arqueológicas en el castro de Sacaojos (Santiago de la Valduerna, León)". $\mathrm{Nu}$ mantia 7: 43-65.

Molina González, F. y Pareja López, E. 1975: Excavaciones en la Cuesta del Negro (Purullena, Granada). Ministerio de Cultura. Madrid.

Morris, J. y Jervis, B. 2011: "What's so special? A reinterpretation of Anglo-Saxon 'Special Deposits"". Medieval Archaeology 55: 66-81.

Needham, S.; Bronk, C.; Coombs, D.; Cartwright, C.; Pettitt, P. 1997: "An independent chronology for British Bronze Age metalwork: the results of the Oxford Radiocarbon Accelerator Programme". Archaeological Journal 154: 55-107.

Quintana López, J. y Cruz Sánchez, P. J. 1996: “Del Bronce al Hierro en el centro de la Submeseta Norte (consideraciones desde el Inventario Arqueológico de Valladolid)". Boletín del Seminario de Estudios de Arte y Arqueología 62: 9-78.

Quintana López, J. y Estremera Portela, M. S. 2008: "La ocupación prehistórica del castro de Peña Amaya (Amaya, Burgos)". Sautuola 14: 107-124.

Reimer, P. J.; Bard, E., Bayliss, A., Beck, J. W., Blackwell, P. G., Bronk Ramsey, C., Grootes, P. M.; Guilderson, T. P., Haflidason, H.; Hajdas, I., Hattz, C.; Heaton, T. J., Hoffman, D. L.; Hogg, A. G.; Hughen, K. A.; Kaiser, F. K.; Kromer, B.; Manning,

Trab. prehist., 71, N. ${ }^{\circ}$ 2, julio-diciembre 2014, pp. 305-329, ISSN: 0082-5638

doi: $10.3989 /$ tp. 2014.12136 
S. W.; Niu, M.; Reimer, R. W.; Richards, D. A.; Scott, E. M.; Southon, J. R.; Staff, R. A.; Turney, C. S. M., y van der Plicht, J. 2013: "IntCall13 and Marine 13 Radiocarbon Calibration Curves, 0-50,000 years cal BP”. Radiocarbon 55 (4): 1869-1887.

Rodríguez Marcos, J. A. 2007: Estudio secuencial de la Edad del Bronce en la Ribera del Duero (provincia de Valladolid). Junta de Castilla y León. Valladolid.

Rosenwig, R. M. 2009: "Early Mesoamerican Garbage: Ceramic and Daub Discard Patterns from Cuauhtémoc, Soconusco, Mexico". Journal of Archaeological Method and Theory 16 (1): 1-32.

Sánchez Polo, A. 2012: "Depósitos de cerámicas, molinos y elementos de hoz: una propuesta de la Edad del Bronce del interior peninsular desde la arqueología posprocesual". Arkeogazte 2: 73-93.

Santonja Gomez, M.; Santonja Alonso, M. y Alcalde, G. 1982: "Aspectos de la ocupación humana antigua del Cañón de la Horadada". Publicaciones de la Institución Tello Téllez de Meneses 47: 337-392.
Schiffer, M. B. 1987: Formation Processes of the Archaeological Record. University of New Mexico Press. Alburquerque.

Sterner, J. 1989: "Who is signalling whom? Ceramic style, ethnicity and taphonomy among the Sirak Bulahay". Antiquity 63: 451-459.

Thomas, J. 1999: Understanding the Neolithic. Routledge. London.

Thomas, J. 2010: "The Return of the Rinyo-Clacton Folk? The Cultural Significance of the Grooved Ware Complex in Later Neolithic Britain". Cambridge Archaeological Journal 20 (1): 1-15.

Ulreich, H.; Negrete, M. A. y Puch, E. 1994: "La cerámica decorada de Hoyas del Castillo (Pajaroncillo, Cuenca). Corte 4". Boletín del Seminario de Estudios de Arte y Arqueología 60: 105-135.

Villa Valdés, A. y Cabo Pérez, L. 2003: "Depósito funerario y recinto fortificado de la Edad del Bronce en el castro del Chao Samartín: argumentos para su datación". Trabajos de Prehistoria 60 (2): 143-141.

Wilson, D. C. 1994: "Identification and assessment of Secondary Refuse Aggregates". Journal of Archaeological Method and Theory 1 (1): 41-68. 